\title{
ETNOBOTÁNICA HISTÓRICA DE GRUPOS CRIOLLOS DE ARGENTINA II: PUESTA EN VALOR, ADSCRIPCIÓN CULTURAL Y ANÁLISIS DE LOS USOS NO MEDICINALES PRESENTADOS POR EL GOBIERNO ARGENTINO EN LA EXPOSICIÓN UNIVERSAL DE PARÍS DE 1889
}

\author{
GUSTAVO F. SCARPA
}

\begin{abstract}
Summary: Scarpa, G. F. 2017. Historical ethnobotany of Criollos groups of Argentina II: Valuation, cultural adscription and analysis of non-medicinal uses presented by the Argentinian Government at the Universal Exhibition of Paris of 1889. Bonplandia 26(1): 77-102.
\end{abstract}

\begin{abstract}
A huge quantity of non-medicinal plant uses registered and exhibited during the Universal Exposition of Paris in 1889 is here put into value, analyzed, and culturally ascribed. Classic methods from historical ethnobotany were applied, considering the catalogue of the Exposition as a primary source of information. Estimated bio-cultural assignment of each one of the 643 ethnobotanical data was inferred from geographic references to seven Argentinian Criollos groups. These data refer to 173 plant taxa, mainly Prosopis nigra, Condalia buxifolia, Enterolobium contortisiliquum, Eugenia uniflora, Anadenanthera colubrina var. cebil, and Prosopis alba. Most plant uses belong to the following categories: dyes (89 data), utensils (87), furniture (87), food (86), transport (77), tanning (52), home building (46), other constructions (35), and fuel. Most data are referred to Criollos from Sub-Andean Valleys of Yungas-Chaco Ecotone (246), the remaining to Criollos from Misiones (142), Criollos from Humid Chaco (100), and Criollos from Arid and Mountainous Chaco (91). Much of these data correspond to little known uses or belong to Criollos groups whose relationships with plants are still incomplete or almost unknown.
\end{abstract}

Key words: Argentina, criollos, $19^{\text {th }}$ century, ethnobotany, non-medicinal uses.

Resumen: Scarpa, G. F. 2017. Etnobotánica histórica de grupos criollos de Argentina II: Puesta en valor, adscripción cultural y análisis de los usos no medicinales presentados por el gobierno argentino en la Exposición Universal de París de 1889. Bonplandia 26(1): 77-102.

Se pone en valor, analiza y adscribe culturalmente el voluminoso corpus de usos no medicinales de las plantas que fueran registrados y exhibidos para la Exposición Universal de París de 1889. Se aplica la metodología propia de la etnobotánica histórica, considerando los datos del catálogo de dicha exposición como fuente de información primaria. A partir de sus referencias geográficas se infiere la adscripción bio-cultural estimada a siete pueblos criollos de la Argentina de cada uno de los 643 datos etnobotánicos registrados. Estos datos aluden a 173 taxones vegetales, principalmente a Prosopis nigra, Condalia buxifolia, Enterolobium contortisiliquum, Eugenia uniflora, Anadenanthera colubrina var. cebil y Prosopis alba. La mayoría de los usos corresponden a las categorías de tintóreas (89 datos); utensilios (87); mobiliario (87); alimentación (86); transporte (77); curtientes (52); viviendas (46); construcciones varias (35) y como combustibles. La mayoría fue referido para los Criollos de Valles Subandinos del ecotono Yungas-Chaco (246), para los Criollos de Misiones (142), para los Criollos del Chaco Húmedo

${ }^{1}$ Museo Argentino de Ciencias Naturales "Bernardino Rivadavia" - CONICET. Av. Ángel Gallardo 470 (C1405DJR), C.A.B.A. E-mail: gscarpa@macn.gov.ar 
(100) y para los Criollos del Chaco Árido y Serrano (91). Se destaca que varios de estos datos corresponden a usos poco relevados, o bien a grupos criollos cuya relación con las plantas todavía nos resulta incompleta o casi desconocida.

Palabras clave: Argentina, criollos, etnobotánica, siglo XIX, usos no-medicinales.

\section{Introducción}

Si bien las investigaciones etnobotánicas en la Argentina han evidenciado un notable incremento desde mediados de 1990 hasta la fecha, las dedicadas a la etnobotánica histórica han mostrado un escaso desarrollo en nuestro país. Entre las obras señeras estrictamente enfocadas en esta temática merecen mencionarse los artículos de Vignati (1941) sobre el "pan" de los patagones protohistóricos, el de Martínez Crovetto (1963) sobre las noticias etnobotánicas de Augusto Guinnard, el de Arenas (1997) sobre las fuentes históricas para su estudio, la tesis doctoral de Cintia Rosso (2012) sobre la etnobotánica de los indígenas mocovíes en las fuentes históricas del jesuita Florian Paucke del siglo XVIII, el trabajo de Anconatani \& Scarpa (2015) sobre la etnobotánica médica de los qom en fuentes documentales de religiosos franciscanos de principios del siglo XX y los de Scarpa \& Rosso (2014a, 2014b) y Martínez Crovetto $(2014 \dagger)$ sobre la etnobotánica de los mocovíes de la provincia del Chaco en los registros de este último autor.

A pesar del desarrollo de la etnobotánica argentina antes mencionado, el conocimiento de los usos y significaciones de las plantas para diversos grupos criollos de nuestro país todavía resulta escaso (Montani \& Scarpa, 2016; Scarpa et al., 2016). Esto es lo que sucede, por ejemplo, con la etnobotánica de los criollos que habitan en los Valles Subandinos del ecotono entre las Yungas y el Chaco, así como con la de los criollos de la provincia de Misiones, a excepción de los realizados por Moreau (2006) y por Keller \& Romero (2006), y la de los criollos del Chaco Árido y Serrano.

Scarpa et al. (2016) ya han reconocido, puesto en valor y analizado un voluminoso corpus de usos medicinales de las plantas exhibidos durante la Exposición Universal de París en 1889, correspondientes a la etnobotánica histórica de criollos del centro- norte de la Argentina y que permanecían prácticamente olvidados. Debido a la imposibilidad de abordar la gran cantidad de datos etnobotánicos presentados durante dicha exposición en un solo artículo, este trabajo se presenta aquí como la segunda parte de aquella contribución. A pesar de que algunos de estos usos vegetales fueron publicados en la obra de Niederlein (1890), donde se describe la exhibición del pabellón argentino en dicha Exposición, la asignación geográfica, y por ende socio-cultural, de la mayoría de estos datos fueron ignorados. Dado el valor que la etnobotánica asigna actualmente a las peculiaridades culturales de cada pueblo en la significación y uso de las plantas, se vuelve significativa la asignación de la información antedicha a cada uno de los pueblos que entonces los refirieron, transformando de esta manera dicha información en datos etnobotánicos propiamente dichos.

El objetivo de esta contribución es describir el voluminoso corpus de usos no medicinales de las plantas que fueran registrados y exhibidos durante la Exposición Universal de París (EUP) de 1889, estimar su adscripción a cada uno de los complejos bio-culturales criollos a los cuales se refiere, y ponderar el valor que los mismos poseen para la etnobotánica argentina de acuerdo a su contexto histórico y cultural de referencia.

\section{Materiales y Métodos}

Los datos sobre usos no medicinales de las plantas exhibidos en el pabellón argentino de la EUP de 1889 fueron recabados por una organización de comisiones auxiliares provinciales coordinada desde la ciudad de Buenos Aires por el prestigioso botánico Gustavo Niederlein, quien dirigió y controló las identificaciones botánicas de los ejemplares que documentaron el corpus de datos 
presentado. Esta verdadera encuesta a nivel nacional fue desarrollada poco antes de 1889 por las comisiones que estuvieron apostadas, mayormente, en las capitales provinciales o de Territorios Nacionales de ese entonces y, en menor medida, en pequeñas localidades del centro-norte de la Argentina. Estos datos fueron publicados en el catálogo oficial de la EUP de 1889, que constituye la fuente histórica primaria de este trabajo, bajo el nombre de "Catalogue spécial. République Argentine. Esposition Internationale de 1889 à Paris", en idioma francés, en aquella misma ciudad y año. En tanto documento histórico extranjero de más de 125 años de antigüedad, y debido a la naturaleza no científica de la publicación, ya que corresponde a un simple catálogo de una exhibición, se comprende que este documento haya tenido escasa disponibilidad, difusión y/o repercusión en nuestro país. Allí se incluyen diferentes usos de las plantas, mencionadas por su nombre científico y su nombre vulgar, indicando para cada caso la provincia o territorio y, en varias ocasiones, la localidad específica de procedencia y el nombre completo de las personas que los refirieron. Esto último, sumado a lo indicado en otras fuentes históricas consultadas, que refieren la organización y preparativos para esta encuesta a nivel nacional (Departamento de Agricultura de la Nación Argentina, 1888), permiten inferir que todas las informaciones presentadas en dicha exposición fueron recogidas "de primera mano" por comisiones provinciales formadas ad hoc.

Todos los datos presentes en dicho catálogo fueron ordenados y sistematizados para su análisis en una base datos según el programa MS-Access.

La metodología de análisis empleada considera a los datos del pasado como fuente de información primaria, a los cuales se aplica la metodología propia de la etnobotánica histórica (Medeiros, 2009; Rosso, 2012; Rosso \& Scarpa, 2012; Scarpa \& Rosso, 2014b). Según esta herramienta resulta imprescindible contextualizar y caracterizar desde el punto de vista histórico las fuentes (quién la realizó, con qué objetivos, en qué marco, etc.), para luego describir y analizar los datos etnobotánicos propiamente dichos.
La adscripción bio-cultural de los datos incluidos en la fuente primaria se estima tanto a partir de datos bibliográficos que refieran la conformación socio-cultural de los grupos humanos que se hallaban presentes en cada uno de los lugares de obtención y/o recopilación de los usos señalados en la EUP en los albores del año 1889, como por las características de la fitonimia y de los tipos de usos de las plantas allí referidos.

Se emplea como criterio metodológico el "axioma bio-cultural" explicitado por Toledo \& Barrera-Bassols (2008), por el cual "cada cultura local interactúa con su propio ecosistema local y con la combinación de paisajes y sus respectivas biodiversidades contenidos en ellos, de tal suerte que el resultado es una compleja y amplia gama de interacciones finas y específicas". A partir de esto último se distinguen complejos bioculturales en función de la información disponible en el Catálogo de la EUP de 1889 y de las inferencias antes detalladas sobre la conformación socio-cultural de cada una de las fuentes de información allí referidas. De esta manera, los datos, por ende, sí pueden considerarse de naturaleza etnobotánica.

Los nombres científicos de los taxones se actualizaron según las bases de datos Flora Argentina (2015) y Tropicos.org (2014) en función de su condición de "aceptado" y se cotejó la validez de su presencia en las regiones geográficas citadas según su distribución actual. Asimismo, se efectuó una estandarización de la nomenclatura de las aplicaciones específicas referidas para cada taxón.

\section{Resultados}

A continuación se describen en términos generales los datos no medicinales presentados en la EUP de 1889, se caracterizan según las categorías de usos más importantes a las que pertenecen las aplicaciones específicas referidas, para luego analizarlos según su adscripción bio-cultural específica estimada. La contextualización histórica del documento utilizado como fuente de los datos, así como el destino del material vegetal de referencia 
que documentan los mismos, no son descriptos aquí en aras de la brevedad, debido a que ya fueron detallados en el trabajo que constituye el precedente inmediato a este (Scarpa et al., 2016).

El número total de datos provenientes de la fuente histórica fue de 732 usos no medicinales asignados a plantas identificadas desde el punto de vista botánico. Un total de 13 de estos datos fueron descartados por hallarse asignados a especies que, según las bases de datos actuales (Flora Argentina, 2015), no se hallan en territorio argentino; 3 de ellos por haber sido asignados a especies explícitamente excluidas de la Flora Argentina y 10 por corresponder a un binomio desconocido tanto para dicha flora como para la base de datos Tropicos.org. (2014). Asimismo, se han verificado algunas incongruencias entre el porte que presentan ciertos taxones citados y algunos de los usos que les son asignados. Entre ellas, figuran los usos maderables asignados a taxones de porte arbustivo tales como Condalia microphylla Cav. (Rhamnaceae), Acnistus australe (Griseb.) Griseb. (Solanaceae) (actualmente Iochroma australe Griseb.); Melochia sp. (Sterculiaceae) y Randia micrantha (Lillo) Bacigalupo (Rubiaceae). En el primer caso, el taxón referido sería indudablemente Condalia buxifolia Reissek, llamado vulgarmente "piquillín grande", pero de porte arbóreo, ya que no solo coincide la correspondencia entre género botánico y nombre vulgar, sino que además algunos de los mismos usos maderables aquí registrados son conocidos y citados en la bibliografía (Demaio et al., 2002) y su distribución coincide con la procedencia de los datos. Debido a esta homologación y por haber sido citados para esta última especie (Demaio et al., 2002), otros usos no maderables referidos para C. microphylla (i.e. "licores", "dulces", etc.) fueron también asignados aquí a C. buxifolia. Los usos referidos a Acnistus australe corresponderían a A. breviflora (actualmente Vassobia breviflora (Sendtn.) Hunz.), por constituir la otra especie del mismo género que tiene porte arbóreo, por ende pasible de poseer usos maderables, y por tener la misma distribución geográfica e idénticos usos citados para el mismo complejo bio-cultural por el catálogo aquí consultado.
En cambio, tanto los usos referidos para Melochia sp. como para Randia micrantha fueron directamente descartados, ya que no concuerdan ni su porte ni su distribución actual con la referida en la fuente histórica de los datos aquí analizada.

Por último, de los 711 datos restantes se pudo verificar que un total de 68 referidos para localidades y/o provincias distintas pertenecían a un mismo complejo bio-cultural criollo, razón por la cual, no se consideran como datos diferentes desde la perspectiva etnobotánica $\mathrm{y}$, por ende, se restan del total mencionado (ver más adelante).

En suma, se reconocen 643 datos etnobotánicos totales referidos a usos no medicinales de pueblos criollos de la Argentina correspondientes a 173 taxones pertenecientes a 56 familias botánicas. En la Tabla 1 se enlistan los usos no medicinales de estas plantas, las que se presentan ordenadas alfabéticamente por familia botánica y nombre científico, nombre criollo, aplicaciones no medicinales específicas, partes utilizadas, localidades y complejo bio-cultural estimado a los que hacen referencia.

El 28,6\% de los datos corresponden a la familia Fabaceae (183); 7,1\% a Rhamnaceae (46); 6,2\% a Myrtaceae (40); 5,3\% a Anacardiaceae (34) y $4,8 \%$ a Rutaceae (31), entre las más importantes. En la Fig. 1 se grafica la participación relativa de las principales especies con usos no medicinales, según cantidad de datos referidos para cada una de ellas.

En la Fig. 2 se representa gráficamente la participación relativa de cada una de las categorías de usos de las plantas en la EUP de 1889, la cual incluye también la correspondiente a "medicinales", publicada en la primer parte de esta investigación (710 datos; $52,5 \%$ ), con el fin de comparar todos los tipos de usos de manera integrada.

En la Fig. 3 se grafica la cantidad de taxones y de usos por taxón (como medida de versatilidad) para cada una de las subcategorías de usos no medicinales.

Los datos etnobotánicos correspondientes a cada una de las aplicaciones específicas no medicinales de las plantas, ordenadas por categorías de uso, se contabilizan en la Tabla 2. 
El Catálogo de la EUP de 1889 refiere datos etnobotánicos no medicinales correspondientes a 14 provincias (o territorios nacionales) de la Argentina. En la Fig. 4 se muestra gráficamente la cantidad y proporción de estos datos para cada una de ellas.

Tal como se afirma en el antecedente principal de este trabajo (Scarpa et al., 2016), a excepción de la provincia de Misiones, no resulta necesario efectuar un estudio histórico detallado a los fines de estimar que los grupos humanos presentes en las localidades de San Salvador de Jujuy, Salta, San Miguel de Tucumán, Córdoba y San Luis durante los albores de 1889, poseían una conformación mayoritariamente Criolla producto de un mestizaje pergeñado desde el siglo XVI. En efecto, desde fines del siglo XVII las poblaciones de dichas localidades quedaron definitivamente "separadas" de los núcleos mayoritariamente indígenas, ya sea por líneas de fortines -y ejecución de campañas punitivas durante todo el siglo XVIII- hacia el este, o por la inaccesibilidad de las áreas montañosas hacia el oeste donde aquellos quedaron encapsulados. Además de la ubicación geográfica de procedencia de los datos, esta inferencia resulta congruente tanto con los nombres vulgares asignados a las plantas -todos criollos- como con la naturaleza típicamente criolla de los usos referidos, según puede consultarse en Scarpa (2012a; 2012b). Respecto a los datos referidos a Misiones en la EUP de 1889, la procedencia socio-cultural de los grupos humanos que allí habitaban podría estimarse -aproximadamente según Scarpa et al. (2016)- a partir de los datos del Censo del Gobierno de Corrientes de 1879 (de quien dependía el distrito de Misiones en esa época). En efecto, según Queirel (1897), en 1879 la mayoría de la población (al menos sus 2/3 partes) correspondía a peones obrajeros, los cuales son explícitamente definidos en la misma fuente histórica como "tanto el nacido y criado allí, como el correntino, brasilero o paraguayo que allí vive y tiene los mismos hábitos y análogo carácter". Estos datos, conjuntamente con la suposición de que la comisión auxiliar haya tenido mayor posibilidad de intercambiar informaciones etnobotánicas con los peones obrajeros - sujetos a un régimen de trabajo asalariado- que con los integrantes de comunidades mbya $-\mathrm{O}$ eventualmente chiripá- guaraníes propiamente dichas -quienes a fines del siglo XIX habrían continuado viviendo en gran medida de los recursos del bosque-, nos permitirían inferir que las informaciones provendrían de la población que conformaría con el tiempo el criollo misionero propiamente dicho. Es decir, se trataría de mestizos cuya conformación socio-cultural sería de raigambre hispanoguaranítica, provenientes tanto de la provincia de Corrientes como de las vecinas Repúblicas de Paraguay y del Brasil.

Los usos no medicinales de las plantas referidos para el "Territorio de Misiones" son adscriptos -de manera estimada- al complejo bio-cultural "Criollos de Misiones", mientras que los datos referidos a "Jujuy", "Tucumán", "Catamarca" (que proceden de las comisiones auxiliares instaladas en sendas capitales provinciales) y Paclín (provincia de Catamarca) al de los "Criollos de Valles Subandinos del ecotono Yungas-Chaco". Los datos registrados en "Formosa" y en "Riacho de Oro" (provincias de Formosa y Chaco respectivamente) son asignados a los "Criollos del Chaco Húmedo". Los datos referidos para Córdoba, en cambio, son adscriptos estimativamente a dos complejos bioculturales distintos: los de "Córdoba", "Anejas Norte" y "Río Segundo" a los "Criollos del Chaco Seco", mientras que los de "Pocho" y "Minas" a los "Criollos del Chaco Árido y Serrano". A este último complejo también son asignados aquellos referidos a "San Luis". Los correspondientes a "La Pampa", "Mercedes" (provincia de Buenos Aires) y "Colonia Helvecia" (provincia de Santa Fe), pertenecerían al complejo bio-cultural de los "Criollos de la región Pampeana", mientras que los de "Mendoza", “Tunuyán” y "Guaymallén" (provincia de Mendoza) a los "Criollos de Cuyo". Por último, el único dato asignado a Santiago del Estero corresponde a los "Criollos del Chaco Seco", mientras que el de Tierra del Fuego queda sin adscribir.

La participación relativa de cada uno los complejos bio-culturales estimados en función de los datos no medicinales registrados en la EUP de 1889 se grafican en la Fig. 5. 
Tabla 1. Datos etnobotánicos no medicinales por Complejos Bio-culturales Criollos estimados (CBC). Table 1. Non-medicinal ethnobotanical data of Criollos bio-cultural complex (CBCE).

\begin{tabular}{|c|c|c|c|c|}
\hline Nombre científico actualizado & $\begin{array}{c}\text { Nombre } \\
\text { vulgar criollo }\end{array}$ & Aplicación específica & Parte usada & $\begin{array}{l}\text { Localidad } \\
\text { referida y CBC }\end{array}$ \\
\hline \multicolumn{5}{|c|}{ LICHENES } \\
\hline \multicolumn{5}{|l|}{ USNEACEAE } \\
\hline \multirow[t]{2}{*}{ Usnea hieronymii Kremp } & $\begin{array}{l}\text { Barba de } \\
\text { piedra }\end{array}$ & Tiñe de anaranjado & To & Córdoba (ChS) \\
\hline & Flor de piedra & Tiñe de anaranjado oscuro & To & Tucumán (CYC) \\
\hline \multirow[t]{3}{*}{ Usnea sp. } & $\begin{array}{l}\text { Barba de } \\
\text { quebracho }\end{array}$ & Tiñe de amarillo claro & To & Córdoba (ChS) \\
\hline & & SPERMATOPHYTA & & \\
\hline & & GIMNOSPERMAE & & \\
\hline \multicolumn{5}{|l|}{ ARAUCARIACEAE } \\
\hline Araucaria angustifolia (Bertol.) & & Muebles y toneles & $\mathrm{Ta}$ & Misiones (CMI) \\
\hline $\begin{array}{l}\text { Kuntze var. angustifolia } \\
\text { (sub Araucaria brasiliana) }\end{array}$ & Pino & $\begin{array}{l}\text { Alimento: Hervidas y para } \\
\text { extraer almidón }\end{array}$ & $\mathrm{Se}$ & Misiones (CMI) \\
\hline \multicolumn{5}{|l|}{ PODOCARPACEAE } \\
\hline \multirow[t]{2}{*}{$\begin{array}{l}\text { Podocarpus parlatorei Pilg. } \\
\text { (sub Podocarpus angustifolia) }\end{array}$} & Pino blanco & Cajas de carretas y viguetas & Ta & $\begin{array}{l}\text { Jujuy y Tucumán } \\
\text { (CYC) }\end{array}$ \\
\hline & & ANGIOSPERMAE & & \\
\hline \multicolumn{5}{|l|}{ ACHATOCARPACEAE } \\
\hline Achatocarpus praecox Griseb. & Runa caspi & Mangos y muebles & $\mathrm{Ta}$ & $\begin{array}{c}\text { Catamarca y } \\
\text { Tucumán (CYC) }\end{array}$ \\
\hline (sub Achatocarpus nigricans) & & Curtiente & Co & Paclín (CYC) \\
\hline \multicolumn{5}{|l|}{ ADOXACEAE } \\
\hline Sambucus nigra L. subsp. & & Dulces & $\mathrm{Fr}$ & Tucumán (CYC) \\
\hline $\begin{array}{l}\text { peruviana (Kunth) R. Bolli } \\
\text { (sub Sambucus peruvianus) }\end{array}$ & Sauco & $\begin{array}{l}\text { Camas, viguetas y leña para } \\
\text { cocinar }\end{array}$ & $\mathrm{Ta}$ & Tucumán (CYC) \\
\hline \multicolumn{5}{|l|}{ ANACARDIACEAE } \\
\hline & & $\begin{array}{l}\text { Tirantes, poleas y sus astillas } \\
\text { tiñen de violeta }\end{array}$ & $\mathrm{Ta}$ & Misiones (CMI) \\
\hline $\begin{array}{l}\text { Astronium urundeuva (Allemâo) } \\
\text { Engl. var. urundeuva }\end{array}$ & Urundey & $\begin{array}{l}\text { Pilares, viguetas y ejes de } \\
\text { carretas }\end{array}$ & $\mathrm{Ta}$ & Formosa $(\mathrm{ChH})$ \\
\hline (sub Astronium juglandifolium) & & $\begin{array}{l}\text { Pilares, viguetas, encatrados } \\
\text { y ejes de carretas }\end{array}$ & $\mathrm{Ta}$ & $\begin{array}{l}\text { Catamarca y } \\
\text { Jujuy (CYC) }\end{array}$ \\
\hline Lithraea molleoides (Vell.) Engl. & & Arados y bateas & $\mathrm{Ta}$ & San Luis (ChAS) \\
\hline \multirow[t]{3}{*}{ (sub Lithraea gilliesii) } & Molle dulce & Dulces y bebidas & $\mathrm{Fr}$ & San Luis (ChAS) \\
\hline & & Curtiente & $\mathrm{Ho}, \mathrm{Se}$ & San Luis (ChAS) \\
\hline & Molle & Tiñe de negro & $?$ & Pocho (ChAS) \\
\hline \multirow[t]{3}{*}{ Schinopsis balansae Engl. } & $\begin{array}{l}\text { Quebracho } \\
\text { colorado }\end{array}$ & Como curtiente y tintóreo & Co, Du & $\begin{array}{l}\text { Riacho de Oro } \\
\quad(\mathrm{ChH})\end{array}$ \\
\hline & & $\begin{array}{l}\text { Viguetas y construcciones } \\
\text { varias }\end{array}$ & $\mathrm{Ta}$ & $\begin{array}{l}\text { Riacho de Oro y } \\
\text { Formosa }(\mathrm{ChH})\end{array}$ \\
\hline & & Curtiente & $\mathrm{Ta}$ & $\begin{array}{l}\text { Santiago del } \\
\text { Estero (ChS) }\end{array}$ \\
\hline \multirow[t]{2}{*}{ Schinopsis lorentzii (Griseb.) Engl. } & $\begin{array}{l}\text { Quebracho } \\
\text { colorado }\end{array}$ & Pilares y cubetas & $\mathrm{Ta}$ & $\begin{array}{l}\text { Tucumán y Jujuy } \\
\text { (CYC) }\end{array}$ \\
\hline & & Curtiente & Co & Paclín (CYC) \\
\hline
\end{tabular}




\begin{tabular}{|c|c|c|c|c|}
\hline Nombre científico actualizado & $\begin{array}{c}\text { Nombre } \\
\text { vulgar criollo }\end{array}$ & Aplicación específica & Parte usada & $\begin{array}{l}\text { Localidad } \\
\text { referida y CBC }\end{array}$ \\
\hline & & Muebles & Ta & Tunuyán (CUY) \\
\hline $\begin{array}{l}\text { Schinus fasciculatus (Griseb.) } \\
\text { I. M. Johnst. var. fasciculatus }\end{array}$ & Molle & Aromatizante de ambientes & Res & Tunuyán (CUY) \\
\hline \multirow[t]{2}{*}{ (sub Duvaua fasciculata) } & & Curtiente & $\begin{array}{l}\mathrm{Ho} \\
\mathrm{Co}\end{array}$ & La Pampa (CPA) \\
\hline & & Dulces y bebidas & $\mathrm{Fr}$ & La Pampa (CPA) \\
\hline Schinus latifolius (Gillies ex & Molle morado & Curtiente & $\mathrm{Ho}, \mathrm{Co}$ & San Luis (ChAS) \\
\hline Lindl.) Engl. & & Muebles & $\mathrm{Ta}$ & San Luis (ChAS) \\
\hline (sub Duavaua latifolia) & Molle de curtir & Tiñe de negro & Ho & Córdoba (ChS) \\
\hline \multirow[t]{2}{*}{ Schinus molle L. var. molle } & Aguaribay & Tiñe de amarillo & Ho & Misiones (CMI) \\
\hline & & Cultivado & To & Mendoza (CUY) \\
\hline $\begin{array}{l}\text { Schinus praecox (Griseb.) Speg. } \\
\text { (sub Duvaua praecox) }\end{array}$ & Molle pispito & Tiñe de color plomo & $?$ & Córdoba (ChS) \\
\hline Schinus sp. & Aroeira & Licor & $\mathrm{Fr}$ & Formosa $(\mathrm{ChH})$ \\
\hline \multicolumn{5}{|l|}{ APOCYNACEAE } \\
\hline \multirow[t]{2}{*}{ Aspidosperma australe Müll. Arg. } & $\begin{array}{l}\text { Guatambú } \\
\text { amarillo }\end{array}$ & Toneles y sillas & Ta & Misiones (CMI) \\
\hline & & $\begin{array}{l}\text { Muebles, cielorrasos, cajas, } \\
\text { timones y mazas de ruedas } \\
\text { de carretas }\end{array}$ & Ta & $\begin{array}{l}\text { Formosa y Riacho } \\
\text { de Oro (ChH) }\end{array}$ \\
\hline \multirow{3}{*}{$\begin{array}{l}\text { Aspidosperma quebracho-blanco } \\
\text { Schltdl. }\end{array}$} & Quebracho & Curtiente & Co & Catamarca (CYC) \\
\hline & blanco & $\begin{array}{l}\text { Aberturas, muebles y cajas } \\
\text { de carretas }\end{array}$ & $\mathrm{Ta}$ & Catamarca (CYC) \\
\hline & & $\begin{array}{l}\text { Muebles, postes y cajas de } \\
\text { carretas }\end{array}$ & $\mathrm{Ta}$ & San Luis (ChAS) \\
\hline \multicolumn{5}{|l|}{ AQUIFOLIACEAE } \\
\hline $\begin{array}{l}\text { Ilex paraguariensis A. St.-Hil. } \\
\text { (sub Ilex bonplandiana) }\end{array}$ & Yerba mate & Mate & Tah & Misiones (CMI) \\
\hline \multicolumn{5}{|l|}{ ARACEAE } \\
\hline $\begin{array}{l}\text { Philodendron bipinnatifidum Schott. } \\
\text { (sub Philodendron sp.) }\end{array}$ & Güembé & Trenzados y cuerdas & Ra?Ta? & Misiones (CMI) \\
\hline \multicolumn{5}{|l|}{ ARECACEAE } \\
\hline $\begin{array}{l}\text { Acrocomia aculeata (Jacq.) Lodd. } \\
\text { ex Mart. }\end{array}$ & Mbocayá & Se comen frescos & $\mathrm{Fr}$ & Misiones (CMI) \\
\hline \multirow[t]{2}{*}{ (sub Acrocomia totay) } & & Cestería & Ho & Misiones (CMI) \\
\hline & & Almidón & $\mathrm{Me}$ & Misiones (CMI) \\
\hline $\begin{array}{l}\text { Copernicia alba Morong } \\
\text { (sub Copernicia cerifera) }\end{array}$ & Palma negra & Postes, pilares y viguetas & Ta & Formosa $(\mathrm{ChH})$ \\
\hline Syagrus romanzoffiana (Cham.) & & Se comen frescos & $\mathrm{Fr}$ & Misiones (CMI) \\
\hline Glassman & Pindó & $\begin{array}{l}\text { Alimento cocido, asado o } \\
\text { crudo }\end{array}$ & $\mathrm{Me}$ & Misiones (CMI) \\
\hline \multirow[t]{2}{*}{ (sub Cocos australis) } & & Techumbres & $\mathrm{Ta}$ & Misiones (CMI) \\
\hline & & Forraje & Ho & Misiones (CMI) \\
\hline \multirow[t]{3}{*}{$\begin{array}{l}\text { Trithrinax campestris (Burmeist.) } \\
\text { Drude \& Griseb. }\end{array}$} & Palmera & $\begin{array}{l}\text { Se comen frescos, como } \\
\text { oleaginosa y se elabora } \\
\text { aguardiente }\end{array}$ & $\mathrm{Fr}$ & San Luis (ChAS) \\
\hline & & Trenzados y abanicos & Ho & San Luis (ChAS) \\
\hline & & Postes & Ta & San Luis (ChAS) \\
\hline \multicolumn{5}{|l|}{ ASTERACEAE } \\
\hline $\begin{array}{l}\text { Acanthostyles buniifolius (Hook. \& } \\
\text { Arn.) R. M. King \& H. Rob. }\end{array}$ & Romerito & Tiñe de verde & $?$ & Minas (ChAS) \\
\hline
\end{tabular}

(sub Eupatorium virgatum)

Romerito 


\begin{tabular}{|c|c|c|c|c|}
\hline Nombre científico actualizado & $\begin{array}{c}\text { Nombre } \\
\text { vulgar criollo }\end{array}$ & Aplicación específica & Parte usada & $\begin{array}{l}\text { Localidad } \\
\text { referida y CBC }\end{array}$ \\
\hline $\begin{array}{l}\text { Baccharis aliena (Spreng.) Joch. } \\
\text { Müll. } \\
\text { (sub Heterothalamus brunioides) }\end{array}$ & Romerillo & Tiñe de amarillo claro & $?$ & $\begin{array}{l}\text { Anejas Norte } \\
\text { (ChS) }\end{array}$ \\
\hline $\begin{array}{l}\text { Baccharis artemisioides Hook. \& } \\
\text { Arn. }\end{array}$ & $\begin{array}{l}\text { Pichana } \\
\text { blanca }\end{array}$ & Tiñe de negro & $?$ & $\begin{array}{l}\text { Anejos Norte } \\
\text { (ChS) }\end{array}$ \\
\hline $\begin{array}{l}\text { Baccharis salicifolia (Ruiz \& Pav.) } \\
\text { Pers. }\end{array}$ & Chilca & Tiñe de amarillo & $?$ & Córdoba (ChS) \\
\hline Baccharis sp. & Clavillo & Tiñe de verde $o$ amarillo & ? & Minas (ChAS) \\
\hline $\begin{array}{l}\text { Chromolaena laevigata (Lam.) R. M. } \\
\text { King \& H. Rob. } \\
\text { (sub Eupatorium laevigatum) }\end{array}$ & Iribú retimá & Tiñe de azulado & Tah & Misiones (CMI) \\
\hline $\begin{array}{l}\text { Flaveria bidentis (L.) Kuntze } \\
\text { (sub Flaveria contrayerba) }\end{array}$ & Chasca & Tiñe de amarillo & $?$ & Córdoba (ChS) \\
\hline Flourensia tortuosa Griseb. & Chilca & Tiñe de amarillo & ? & Minas (ChAS) \\
\hline Parthenium hysterophorus L. & $\begin{array}{l}\text { Yerba de la } \\
\text { oveja }\end{array}$ & Tiñe de verde pálido & $?$ & La Pampa (CPA) \\
\hline Pectis odorata Griseb. & $\begin{array}{l}\text { Manzanilla } \\
\text { del campo }\end{array}$ & Tiñe de amarillo & Tah & La Pampa (CPA) \\
\hline Solidago microglossa DC. & $\begin{array}{l}\text { Mbuy o yerba } \\
\text { lanceta }\end{array}$ & Tiñe de amarillo & $\mathrm{FI}$ & Misiones (CMI) \\
\hline \multicolumn{5}{|l|}{ BERBERIDACEAE } \\
\hline $\begin{array}{l}\text { Berberis lilloana Job } \\
\text { (sub Berberis flexuosa) }\end{array}$ & Sacha uva & Tiñe de verde o amarillo & $\mathrm{Ra}$ & Tucumán (CYC) \\
\hline Berberis ruscifolia Lam. & Quebrachillo & Curtiente & $\mathrm{Ra}$ & San Luis (ChAS) \\
\hline \multicolumn{5}{|l|}{ BETULACEAE } \\
\hline $\begin{array}{l}\text { Alnus acuminata Kunth } \\
\text { (sub Alnus ferruginosa) }\end{array}$ & Aliso & $\begin{array}{l}\text { Armazones, puertas, } \\
\text { muebles y embarcaciones }\end{array}$ & $\mathrm{Ta}$ & Tucumán (CYC) \\
\hline \multicolumn{5}{|l|}{ BIGNONIACEAE } \\
\hline $\begin{array}{l}\text { Handroanthus impetiginosus (Mart. } \\
\text { ex DC.) Mattos }\end{array}$ & Lapacho & $\begin{array}{l}\text { Muebles, yugos, mazas y } \\
\text { Ilantas de ruedas de carretas }\end{array}$ & $\mathrm{Ta}$ & $\begin{array}{l}\text { Catamarca y } \\
\text { Tucumán (CYC) }\end{array}$ \\
\hline \multirow[t]{2}{*}{ (sub Tabebuia avellanedae) } & & Para teñir & Du & Catamarca (CYC) \\
\hline & & Curtiente & Co & Paclín (CYC) \\
\hline $\begin{array}{l}\text { Handroanthus lapacho (K. Schum.) } \\
\text { S. Grose }\end{array}$ & Lapacho & $\begin{array}{l}\text { Muebles, encatrados y } \\
\text { construcciones varias }\end{array}$ & $\mathrm{Ta}$ & $\begin{array}{l}\text { Riacho de Oro y } \\
\text { Formosa }(\mathrm{ChH})\end{array}$ \\
\hline (sub Tabebuia flavescens) & $\begin{array}{l}\text { Lapacho } \\
\text { crespo }\end{array}$ & $\begin{array}{l}\text { Cajas de carretas y sus } \\
\text { astillas tiñen de rojo o } \\
\text { amarillo }\end{array}$ & $\mathrm{Ta}$ & Misiones (CMI) \\
\hline $\begin{array}{l}\text { Jacaranda caroba (Vell.) DC. } \\
\text { (sub Bignonia caroba) }\end{array}$ & Caroba & Tiñe de colorado & Co & Misiones (CMI) \\
\hline Tabebuia sp. & $\begin{array}{l}\text { Lapacho } \\
\text { negro }\end{array}$ & Cajas de carretas & $\mathrm{Ta}$ & Misiones (CMI) \\
\hline Tebebuia nodosa (Griseb.) Griseb. & Palo mataco & Picas, bastones y cañas & Ta & Jujuy (CYC) \\
\hline Tecoma stans (L.) Juss. ex Kunth & $\begin{array}{l}\text { Guaranguay } \\
\text { blanco }\end{array}$ & Cajas de carretas & $\mathrm{Ta}$ & Jujuy (CYC) \\
\hline \multicolumn{5}{|l|}{ BOMBACACEAE } \\
\hline & & $\begin{array}{l}\text { Almohadillas, pabilos, sacos } \\
\text { o bolsas, hilado y tejido }\end{array}$ & $\mathrm{Se}$ & Catamarca (CYC) \\
\hline \multirow[t]{2}{*}{$\begin{array}{l}\text { Ceiba insignis (Kunth) P. E. Gibbs } \\
\text { \& Semir }\end{array}$} & $\begin{array}{l}\text { Palo de } \\
\text { borracho }\end{array}$ & Toneles & $\mathrm{Ta}$ & $\begin{array}{l}\text { Catamarca y } \\
\text { Tucumán (CYC) }\end{array}$ \\
\hline & & Cuerdas & Co & Catamarca (CYC) \\
\hline \multirow[t]{4}{*}{ (sub Chorisia insignis) } & Yuchán & Algodón sedoso & $\mathrm{Se}$ & Tucumán (CYC) \\
\hline & & Tejidos rústicos & Co & Tucumán (CYC) \\
\hline & Samohú & Algodón sedoso & $\mathrm{Se}$ & Formosa $(\mathrm{ChH})$ \\
\hline & & Cuerdas & Co & Formosa (ChH) \\
\hline
\end{tabular}




\begin{tabular}{|c|c|c|c|c|}
\hline Nombre científico actualizado & $\begin{array}{c}\text { Nombre } \\
\text { vulgar criollo }\end{array}$ & Aplicación específica & Parte usada & $\begin{array}{l}\text { Localidad } \\
\text { referida y CBC }\end{array}$ \\
\hline $\begin{array}{l}\text { Ceiba speciosa (A. St.-Hil., A. Juss. } \\
\text { \& Cambess.) Ravenna } \\
\text { (sub Chorisia sp.) }\end{array}$ & Samohú & $\begin{array}{l}\text { Algodón sedoso, hilado y } \\
\text { tejido }\end{array}$ & $\mathrm{Se}$ & Misiones (CMI) \\
\hline \multicolumn{5}{|l|}{ BORAGINACEAE } \\
\hline $\begin{array}{l}\text { Cordia americana (L.) Gottschling \& } \\
\text { J. S. Mill. }\end{array}$ & $\begin{array}{l}\text { Guagubirá } \\
\text { negro }\end{array}$ & $\begin{array}{l}\text { Mangos, muebles, cajas de } \\
\text { carretas, yugos, }\end{array}$ & $\mathrm{Ta}$ & Misiones (CMI) \\
\hline (sub Patagonula americana) & $\begin{array}{l}\text { Guayabí } \\
\text { blanco }\end{array}$ & $\begin{array}{l}\text { Mangos, palas, muebles, } \\
\text { embarcaciones, remos y } \\
\text { pértigas }\end{array}$ & $\mathrm{Ta}$ & $\begin{array}{l}\text { Formosa y Riacho } \\
\text { de Oro (ChH) }\end{array}$ \\
\hline $\begin{array}{l}\text { Cordia trichotoma (Vell.) Arráb. ex } \\
\text { Steud. } \\
\text { (sub Cordia sp.) }\end{array}$ & Loro amarillo & Muebles & $\mathrm{Ta}$ & Misiones (CMI) \\
\hline \multicolumn{5}{|l|}{ BROMELIACEAE } \\
\hline Bromelia serra Griseb. & Chaguar & Textil & Ho & Córdoba (ChS) \\
\hline \multicolumn{5}{|l|}{ CACTACEAE } \\
\hline \multirow[t]{3}{*}{ Cereus sp. } & Tuna & Tiñe de verde & Co & Misiones (CMI) \\
\hline & & Se comen frescos & $\mathrm{Fr}$ & Misiones (CMI) \\
\hline & & Se comen frescos & $\mathrm{Fr}$ & Formosa (ChH) \\
\hline \multicolumn{5}{|l|}{ CAPPARACEAE } \\
\hline $\begin{array}{l}\text { Capparis atamisquea Kuntze } \\
\text { (sub Atamisquea emarginata) }\end{array}$ & Atamisque & Tiñe de color plomo & $?$ & Tucumán (CYC) \\
\hline \multicolumn{5}{|l|}{ CARICACEAE } \\
\hline Carica quercifolia (A. St.-Hil.) Hieron. & $\begin{array}{l}\text { Nacaratiá } \\
\text { menor }\end{array}$ & Se comen frescos & $\mathrm{Fr}$ & Misiones (CMI) \\
\hline $\begin{array}{l}\text { Jacaratia spinosa (Aubl.) A. DC. } \\
\text { (sub Carica (Vasconcellia) } \\
\text { dodecaphylla) }\end{array}$ & Nacaratiá & Se comen frescos & $\mathrm{Fr}$ & Misiones (CMI) \\
\hline \multicolumn{5}{|l|}{ CELTIDACEAE } \\
\hline \multirow[t]{3}{*}{$\begin{array}{l}\text { Celtis brasiliensis (Gardner) Planch. } \\
\text { (sub Celtis flexuosa) }\end{array}$} & $\begin{array}{c}\text { Tala } \\
\text { gateadora }\end{array}$ & Cercos ganaderos & $\mathrm{Ta}$ & Jujuy (CYC) \\
\hline & & $\begin{array}{l}\text { Ejes de carretas, látigos, } \\
\text { leña de calefacción, mangos, } \\
\text { bastones y cañas }\end{array}$ & $\mathrm{Ta}$ & $\begin{array}{l}\text { Tucumán y Jujuy } \\
\text { (CYC) }\end{array}$ \\
\hline & & Tiñe de castaño claro & $\mathrm{Ra}$ & Tucumán (CYC) \\
\hline $\begin{array}{l}\text { Celtis ehrenbergiana (Klotzsch) } \\
\text { Liebm. var. ehrenbergiana }\end{array}$ & Tala & $\begin{array}{l}\text { Ejes de carretas, látigos, } \\
\text { mangos, leña de calefacción } \\
\text { y postes }\end{array}$ & $\mathrm{Ta}$ & San Luis (ChAS) \\
\hline \multirow[t]{4}{*}{ (sub Celtis tala) } & & Tiñe de castaño claro & $\mathrm{Ra}$ & San Luis (ChAS) \\
\hline & & Se comen frescos & $\mathrm{Fr}$ & Misiones (CMI) \\
\hline & & Se comen frescos & $\mathrm{Fr}$ & Formosa $(\mathrm{ChH})$ \\
\hline & & Leña calefacción y mangos & $\mathrm{Ta}$ & Formosa (ChH) \\
\hline Trema micrantha (L.) Blume & $\begin{array}{l}\text { Afata } \\
\text { colorada }\end{array}$ & Viguetas & $\mathrm{Ta}$ & Tucumán (CYC) \\
\hline (sub Trema sp.) & Grindiuva & Tejidos rústicos & $\mathrm{Ta}$ ? & Misiones (CMI) \\
\hline \multicolumn{5}{|l|}{ CERVANTESIACEAE } \\
\hline Jodina rhombifolia (Hook. \& Arn.) & $\begin{array}{l}\text { Quebracho } \\
\text { flojo }\end{array}$ & Ejes de carretas & $\mathrm{Ta}$ & San Luis (ChAS) \\
\hline Reissek & $\begin{array}{l}\text { Sombra de } \\
\text { toro }\end{array}$ & Viguetas, muebles y yugos & $\mathrm{Ta}$ & $\begin{array}{l}\text { Tucumán y Jujuy } \\
\text { (CYC) }\end{array}$ \\
\hline \multicolumn{5}{|l|}{ CHENOPODIACEAE } \\
\hline $\begin{array}{l}\text { Allenrolfea patagonica (Moq.) } \\
\text { Kuntze } \\
\text { (sub Spirotachys patagonica) }\end{array}$ & Jume & Jabón & Cen & Tucumán (CYC) \\
\hline
\end{tabular}




\begin{tabular}{|c|c|c|c|c|}
\hline Nombre científico actualizado & $\begin{array}{c}\text { Nombre } \\
\text { vulgar criollo }\end{array}$ & Aplicación específica & Parte usada & $\begin{array}{l}\text { Localidad } \\
\text { referida y CBC }\end{array}$ \\
\hline $\begin{array}{l}\text { Dysphania ambrosioides (L.) } \\
\text { Mosyakin \& Clemants } \\
\text { (sub Chenopodium anthelminticum) }\end{array}$ & Quina & Lejía para jabón & Cen & Córdoba (ChS) \\
\hline \multirow[t]{2}{*}{ Suaeda divaricata Moq. } & Jume & Jabón & Cen & Tucumán (CYC) \\
\hline & & Jabón & Cen & Mendoza (CUY) \\
\hline \multicolumn{5}{|l|}{ COMBRETACEAE } \\
\hline Terminalia australis Cambess. & Amarillo & Para hacer carbón & $\mathrm{Ta}$ & Tucumán (CYC) \\
\hline \multirow[t]{2}{*}{ Terminalia triflora (Griseb.) Lillo } & $\begin{array}{l}\text { Lanza } \\
\text { amarilla, Palo } \\
\text { amarillo }\end{array}$ & $\begin{array}{l}\text { Leña para calefacción y para } \\
\text { cocinar, muebles, pilares, } \\
\text { ejes de carretas, mangos, } \\
\text { sillas y para hacer carbón }\end{array}$ & $\mathrm{Ta}$ & $\begin{array}{c}\text { Tucumán y } \\
\text { Catamarca (CYC) }\end{array}$ \\
\hline & Palo amarillo & Muebles y talladuras & $\mathrm{Ta}$ & $\begin{array}{l}\text { Riacho de Oro } \\
\quad(\mathrm{ChH})\end{array}$ \\
\hline \multicolumn{5}{|l|}{ EUPHORBIACEAE } \\
\hline \multirow[t]{2}{*}{$\begin{array}{l}\text { Croton urucurana Baill. } \\
\text { (sub Croton succirubrus) }\end{array}$} & $\begin{array}{l}\text { Sangre de } \\
\text { drago }\end{array}$ & Curtiente & Co & Misiones (CMI) \\
\hline & & Tiñe de rojo & Res & Misiones (CMI) \\
\hline Sapium haematospermum Müll. & Lecherón & Platos y bandejas & $\mathrm{Ta}$ & Jujuy (CYC) \\
\hline $\begin{array}{l}\text { Arg. } \\
\text { (sub Sapium aucuparium) }\end{array}$ & Higuerón & Veneno para flechas & La & Tucumán (CYC) \\
\hline $\begin{array}{l}\text { Sebastiania brasiliensis Spreng. } \\
\text { (sub Actinostemon anisandrus) }\end{array}$ & Leche leche & Yugos & $\mathrm{Ta}$ & Jujuy (CYC) \\
\hline $\begin{array}{l}\text { Sebastiania commersoniana (Baill.) } \\
\text { L. B. Sm. \& Downs } \\
\text { (sub Sebastiana klotziana) }\end{array}$ & Blanquillo & Para hacer carbón & $\mathrm{Ta}$ & Misiones (CMI) \\
\hline \multicolumn{5}{|l|}{ FABACEAE } \\
\hline & & Perfumería & $\mathrm{FI}$ & Tucumán (CYC) \\
\hline Acacia aroma Gillies ex Hook. \& Arn. & Tusca & $\begin{array}{l}\text { Muebles, leña para } \\
\text { calefacción }\end{array}$ & $\mathrm{Ta}$ & $\begin{array}{l}\text { Tucumán y Jujuy } \\
\text { (CYC) }\end{array}$ \\
\hline (sub Acacia aroma var. & & Forraje & $\mathrm{Fr}$ & Jujuy (CYC) \\
\hline \multirow[t]{2}{*}{ moniliformis) } & $\begin{array}{c}\text { Espinillo } \\
\text { blanco }\end{array}$ & Forraje & Ho & San Luis (ChAS) \\
\hline & & Leña para calefacción & $\mathrm{Ta}$ & San Luis (ChAS) \\
\hline \multirow[t]{3}{*}{ Acacia atramentaria Benth. } & Algarrobilla & Curtiente & $\mathrm{Se}$ & San Luis (ChAS) \\
\hline & & Tiñe de negro & $?$ & Minas (ChAS)) \\
\hline & $\begin{array}{l}\text { Churqui } \\
\text { negro }\end{array}$ & $\begin{array}{l}\text { Leña para calefacción, para } \\
\text { carbón, postes y yugos }\end{array}$ & $\mathrm{Ta}$ & Tucumán (CYC) \\
\hline \multirow{3}{*}{$\begin{array}{l}\text { Acacia caven (Molina) Molina var. } \\
\text { caven }\end{array}$} & & Perfumería & $\mathrm{FI}$ & Tucumán (CYC) \\
\hline & & Lejía para jabón & Cen & Tucumán (CYC) \\
\hline & & Puertas y leña para cocinar & $\mathrm{Ta}$ & Formosa $(\mathrm{ChH})$ \\
\hline \multirow[t]{2}{*}{ (sub Acacia cavenia) } & Espinillo & Postes & $\mathrm{Ta}$ & Misiones (CMI) \\
\hline & & Curtiente & $\mathrm{Co}, \mathrm{Fr}$ & Misiones (CMI) \\
\hline Acacia sp. & Palo barroso & Viguetas & $\mathrm{Ta}$ & Jujuy (CYC) \\
\hline Acacia tucumanensis Griseb. & Yuquirí & Mangos & $\mathrm{Ta}$ & Formosa $(\mathrm{ChH})$ \\
\hline (sub Acacia riparia var. tucumanesis) & Garrabato & Mangos & $\mathrm{Ta}$ & Tucumán (CYC) \\
\hline \multirow[t]{2}{*}{ Acacia visco Lorentz ex Griseb. } & Arca & Muebles & $\mathrm{Ta}$ & Tucumán (CYC) \\
\hline & & $\begin{array}{l}\text { Postes, mangos, viguetas, } \\
\text { toneles }\end{array}$ & $\mathrm{Ta}$ & Misiones (CMI) \\
\hline $\begin{array}{l}\text { Anadenanthera colubrina (Vell.) } \\
\text { Brenan var. cebil (Griseb.) }\end{array}$ & Curupay & $\begin{array}{l}\text { Curtiente y tiñe de pardo- } \\
\text { rojizo }\end{array}$ & Co & Misiones (CMI) \\
\hline \multirow[t]{2}{*}{ Altschul } & & Muebles, postes y viguetas & $\mathrm{Ta}$ & Formosa $(\mathrm{ChH})$ \\
\hline & & Curtiente & Co & Formosa $(\mathrm{ChH})$ \\
\hline
\end{tabular}




\begin{tabular}{|c|c|c|c|c|}
\hline Nombre científico actualizado & $\begin{array}{c}\text { Nombre } \\
\text { vulgar criollo }\end{array}$ & Aplicación específica & Parte usada & $\begin{array}{l}\text { Localidad } \\
\text { referida y CBC }\end{array}$ \\
\hline \multirow[t]{3}{*}{ (sub Piptadenia cebil) } & Cebil & Curtiente & Co & $\begin{array}{l}\text { Jujuy, Tucumán y } \\
\text { Catamarca (CYC) }\end{array}$ \\
\hline & & Bateas, postes y tinajas & $\mathrm{Ta}$ & $\begin{array}{l}\text { Jujuy, Tucumán y } \\
\text { Catamarca (CYC) }\end{array}$ \\
\hline & & $\begin{array}{l}\text { Mangos, muebles, llantas y } \\
\text { mazas de carretas }\end{array}$ & $\mathrm{Ta}$ & $\begin{array}{c}\text { Tucumán y } \\
\text { Catamarca (CYC) }\end{array}$ \\
\hline $\begin{array}{l}\text { Caesalpinia paraguariensis (D. } \\
\text { Parodi) Burkart }\end{array}$ & Guayacán & Curtiente & Co, Fr & $\begin{array}{c}\text { Tucumán y } \\
\text { Catamarca (CYC) }\end{array}$ \\
\hline \multirow[t]{2}{*}{ (sub Caesalpinia melanocarpa) } & & Tiñe de negro & $\mathrm{Fr}$ & Tucumán (CYC) \\
\hline & & Para teñir & Res & Catamarca (CYC) \\
\hline Cercidium praecox (Ruiz \& Pav. & & Aromatizante de ambientes & Co & La Pampa (CPA) \\
\hline $\begin{array}{l}\text { ex Hook.) Harms } \\
\text { (sub Caesalpinia praecox) }\end{array}$ & Brea & Goma de pegar & Res & La Pampa (CPA) \\
\hline Chloroleucon tenuiflorum & Espinillo & $\begin{array}{l}\text { Culatas de rifles, muebles y } \\
\text { toneles }\end{array}$ & $\mathrm{Ta}$ & $\begin{array}{l}\text { Tucumán y Jujuy } \\
\text { (CYC) }\end{array}$ \\
\hline (Benth.) Barneby \& J. W. Grimes & Tatané & Muebles & Ta & Misiones (CMI) \\
\hline \multirow[t]{4}{*}{ (sub Pithecellobium tortum) } & $\begin{array}{l}\text { Ivirá iné, } \\
\text { Tatané }\end{array}$ & $\begin{array}{l}\text { Embarcaciones, muebles } \\
\text { finos y rústicos }\end{array}$ & $\mathrm{Ta}$ & $\begin{array}{l}\text { Riacho de Oro y } \\
\text { Formosa }(\mathrm{ChH})\end{array}$ \\
\hline & & $\begin{array}{l}\text { Embarcaciones, muebles y } \\
\text { tinajas }\end{array}$ & $\mathrm{Ta}$ & $\begin{array}{l}\text { Riacho de Oro y } \\
\text { Formosa }(\mathrm{ChH})\end{array}$ \\
\hline & & Para teñir & $\mathrm{Ra}$ & Formosa $(\mathrm{ChH})$ \\
\hline & Timbó & Curtiente & Co & Formosa $(\mathrm{ChH})$ \\
\hline Enterolobium contortisiliquum & & Detergente y curtiente & Co & Misiones (CMI) \\
\hline \multirow[t]{2}{*}{ (Vell.) Morong } & & Tiñe de negro & $\mathrm{Fr}$ & Misiones (CMI) \\
\hline & & Curtiente y tiñe de negro & $\mathrm{Fr}$ & $\begin{array}{l}\text { Catamarca y } \\
\text { Tucumán (CYC) }\end{array}$ \\
\hline \multirow[t]{4}{*}{ (sub Enterolobium timbouva Mart.) } & Pacará & $\begin{array}{l}\text { Culatas de rifles, muebles, } \\
\text { puertas, embarcaciones y } \\
\text { toneles }\end{array}$ & $\mathrm{Ta}$ & $\begin{array}{l}\text { Tucumán y Jujuy } \\
\text { (CYC) }\end{array}$ \\
\hline & Pacará plomo & Detergente y curtiente & Co & $\begin{array}{l}\text { Tucumán y Jujuy } \\
\text { (CYC) }\end{array}$ \\
\hline & & $\begin{array}{l}\text { Tiñe de rosa, colorado o } \\
\text { encarnado }\end{array}$ & $\mathrm{FI}$ & Misiones (CMI) \\
\hline & & Bateas & $\mathrm{Ta}$ & Misiones (CMI) \\
\hline \multirow[t]{4}{*}{ Erythrina crista-galli L. } & Ceibo & Para teñir & $\mathrm{FI}$ & Tucumán (CYC) \\
\hline & & Tostadas como alimento & $\mathrm{FI}$ & Jujuy (CYC) \\
\hline & & Embarcaciones & Тa & Formosa $(\mathrm{ChH})$ \\
\hline & & $\begin{array}{l}\text { Se comen frescos y en } \\
\text { dulces }\end{array}$ & $\mathrm{Fr}$ & Tucumán (CYC) \\
\hline \multirow[t]{2}{*}{$\begin{array}{l}\text { Geoffroea decorticans (Gillies ex } \\
\text { Hook. \& Arn.) Burkart }\end{array}$} & & $\begin{array}{l}\text { Mangos, muebles y leña de } \\
\text { calefacción }\end{array}$ & $\mathrm{Ta}$ & Tucumán (CYC) \\
\hline & & Dulces & $\mathrm{Fr}$ & La Pampa (CPA) \\
\hline \multirow[t]{3}{*}{ (sub Gourliea decorticans) } & Chañar & $\begin{array}{l}\text { Construcciones varias, } \\
\text { mangos y muebles }\end{array}$ & $\mathrm{Ta}$ & La Pampa (CPA) \\
\hline & & $\begin{array}{l}\text { Leña para calefacción y } \\
\text { mangos }\end{array}$ & $\mathrm{Ta}$ & San Luis (ChAS) \\
\hline & & $\begin{array}{l}\text { Se comen frescos y se } \\
\text { elaboran bebidas }\end{array}$ & $\mathrm{Fr}$ & San Luis (ChAS) \\
\hline \multirow[t]{2}{*}{$\begin{array}{l}\text { Gleditsia amorphoides (Griseb.) } \\
\text { Taub. var. amorphoides }\end{array}$} & $\begin{array}{l}\text { Espina de } \\
\text { corona }\end{array}$ & Detergente & Co & Misiones (CMI) \\
\hline & & Construcciones varias & $\mathrm{Ta}$ & Jujuy (CYC) \\
\hline \multirow[t]{2}{*}{ (sub Garugandra amorphoides) } & Coronillo & Detergente & Co & Jujuy (CYC) \\
\hline & & Arcos de flechas y muebles & $\mathrm{Ta}$ & Misiones (CMI) \\
\hline Holocalyx balansae Micheli & Alecrín & Arcos de flechas & $\mathrm{Ta}$ & Misiones (CMI) \\
\hline
\end{tabular}




\begin{tabular}{|c|c|c|c|c|}
\hline Nombre científico actualizado & $\begin{array}{c}\text { Nombre } \\
\text { vulgar criollo }\end{array}$ & Aplicación específica & Parte usada & $\begin{array}{l}\text { Localidad } \\
\text { referida y СВC }\end{array}$ \\
\hline $\begin{array}{l}\text { Indigofera suffruticosa Mill. } \\
\text { (sub Indogofera anil) }\end{array}$ & Anilina & Tiñe de azulado & $?$ & Córdoba (ChS) \\
\hline \multirow{2}{*}{$\begin{array}{l}\text { Inga marginata Willd. } \\
\text { (sub Inga fagifolia) }\end{array}$} & Ingá dulce & Se comen frescos & $\mathrm{Fr}$ & Misiones (CMI) \\
\hline & & Se comen frescos & $\mathrm{Fr}$ & Formosa $(\mathrm{CCH})$ \\
\hline \multirow[t]{2}{*}{ Inga uraguensis Hook. \& Arn. } & Ingá & Curtiente & $?$ & Misiones (CMI) \\
\hline & & Muebles rústicos & Ta & Misiones (CMI) \\
\hline $\begin{array}{l}\text { Mimosa detinens Benth. } \\
\text { (sub Mimosa lorentzii) }\end{array}$ & $\begin{array}{l}\text { Garabato } \\
\text { (grande) }\end{array}$ & $\begin{array}{l}\text { Mangos y leña de } \\
\text { calefacción }\end{array}$ & $\mathrm{Ta}$ & $\begin{array}{l}\text { Rio Segundo } \\
\text { (ChS) }\end{array}$ \\
\hline $\begin{array}{l}\text { Mimozyganthus carinatus (Griseb.) } \\
\text { Burkart } \\
\text { (sub Mimosa carinata) }\end{array}$ & Lata & Mangos y leña de calidad & Ta & San Luis (ChAS) \\
\hline $\begin{array}{l}\text { Parapiptadenia excelsa (Griseb.) } \\
\text { Burkart } \\
\text { (sub Piptadenia communis) }\end{array}$ & $\begin{array}{l}\text { Horco cebil, } \\
\text { Cebil blanco }\end{array}$ & $\begin{array}{l}\text { Pértigas, pilares, viguetas y } \\
\text { carrocerías de carretas }\end{array}$ & Ta & $\begin{array}{l}\text { Catamarca, Jujuy } \\
\text { y Tucumán (CYC) }\end{array}$ \\
\hline $\begin{array}{l}\text { Parapiptadenia rigida (Benth.) } \\
\text { Brenan } \\
\text { (sub Acacia angico) }\end{array}$ & $\begin{array}{l}\text { Anchico } \\
\text { colorado }\end{array}$ & $\begin{array}{l}\text { Carrocerías de carretas, } \\
\text { curtiente, poleas y muebles }\end{array}$ & $\mathrm{Ta}$ & Misiones (CMI) \\
\hline Peltophorum dubium (Spreng.) Taub. & Ibirápytá & Ruedas y embarcaciones & Ta & $\begin{array}{l}\text { Riacho de Oro y } \\
\text { Formosa (ChH) }\end{array}$ \\
\hline \multirow[t]{4}{*}{ (sub Peltophorum vogelianum) } & Cañafístula & Puertas, toneles y viguetas & $\mathrm{Ta}$ & Misiones (CMI) \\
\hline & & Curtiente y tiñe de violeta & Ta, Co & Misiones (CMI) \\
\hline & Algarrobo & Aberturas y muebles & $\mathrm{Ta}$ & $\begin{array}{l}\text { Riacho de Oro } \\
\text { (ChH) }\end{array}$ \\
\hline & & $\begin{array}{l}\text { Se comen frescos y en } \\
\text { añapa }\end{array}$ & $\mathrm{Fr}$ & Formosa $(\mathrm{ChH})$ \\
\hline \multirow[t]{6}{*}{ Prosopis alba Griseb. var. alba } & $\begin{array}{l}\text { Algarrobo } \\
\text { blanco }\end{array}$ & $\begin{array}{l}\text { Se comen frescos y en } \\
\text { añapa }\end{array}$ & $\mathrm{Fr}$ & $\begin{array}{l}\text { Catamarca y } \\
\text { Jujuy (CYC) }\end{array}$ \\
\hline & & $\begin{array}{l}\text { Aberturas, encatrados, } \\
\text { muebles, cajas y ruedas de } \\
\text { carros y carretas }\end{array}$ & $\mathrm{Ta}$ & $\begin{array}{l}\text { Catamarca y } \\
\text { Jujuy (CYC) }\end{array}$ \\
\hline & & Curtiente & Co & Jujuy (CYC) \\
\hline & & $\begin{array}{l}\text { Construcciones varias y } \\
\text { puertas }\end{array}$ & $\mathrm{Ta}$ & San Luis (ChAS) \\
\hline & & Se prepara aloja & $\mathrm{Fr}$ & San Luis (ChAS) \\
\hline & & Curtiente & Co & San Luis (ChAS) \\
\hline $\begin{array}{l}\text { Prosopis alba Griseb. var. panta } \\
\text { Griseb. }\end{array}$ & $\begin{array}{l}\text { Algarrobo } \\
\text { panta }\end{array}$ & Encatrados & $\mathrm{Ta}$ & $\begin{array}{l}\text { Rio Segundo } \\
\text { (ChS) }\end{array}$ \\
\hline \multirow[t]{2}{*}{ (sub Prosopis panta) } & & Tiñe de castaño claro & $\mathrm{Ra}$ & Córdoba (ChS) \\
\hline & & Bateas, muebles y postes & Ta & San Luis (ChAS) \\
\hline Prosopis caldenia Burkart & Caldén & Curtiente & $\mathrm{Fr}$ & San Luis (ChAS) \\
\hline \multirow[t]{2}{*}{ (sub Prosopis algarrobilla) } & & Construcciones varias & Ta & La Pampa (CPA) \\
\hline & & Forraje & $\mathrm{Fr}$ & La Pampa (CPA) \\
\hline \multirow[t]{6}{*}{ Prosopis ferox Griseb. } & $\begin{array}{l}\text { Churqui } \\
\text { blanco }\end{array}$ & Leña calefacción y yugos & Ta & Tucumán (CYC) \\
\hline & Algarrobo & Construcciones varias & $\mathrm{Ta}$ & La Pampa (CPA) \\
\hline & & $\begin{array}{l}\text { Aberturas, muebles, puertas } \\
\text { y embarcaciones }\end{array}$ & Ta & Formosa $(\mathrm{ChH})$ \\
\hline & & $\begin{array}{l}\text { Carrocerías de carretas, } \\
\text { encatrados y pilares }\end{array}$ & $\mathrm{Ta}$ & Jujuy (CYC) \\
\hline & & Aberturas y puertas & Ta & San Luis (ChAS) \\
\hline & & Curtiente & Co & San Luis (ChAS) \\
\hline \multirow[t]{2}{*}{ Prosopis nigra (Griseb.) Hieron. } & Algarrobo & Tinta para escribir & Res & San Luis (ChAS) \\
\hline & & Arrope medicinal y dulces & $\mathrm{Fr}$ & San Luis (ChAS) \\
\hline
\end{tabular}




\begin{tabular}{|c|c|c|c|c|}
\hline Nombre científico actualizado & $\begin{array}{c}\text { Nombre } \\
\text { vulgar criollo }\end{array}$ & Aplicación específica & Parte usada & $\begin{array}{l}\text { Localidad } \\
\text { referida y CBCE }\end{array}$ \\
\hline & & Aberturas, viviendas & Ta & $\begin{array}{l}\text { Cnia. Helvecia } \\
\text { (CPA) }\end{array}$ \\
\hline & & Se comen en añapa y patay & $\mathrm{Fr}$ & $\begin{array}{l}\text { Cnia. Helvecia } \\
\text { (CPA) }\end{array}$ \\
\hline Prosopis sp. & $\begin{array}{l}\text { Algarrobo } \\
\text { morado }\end{array}$ & Muebles y postes & $\mathrm{Ta}$ & Jujuy (CYC) \\
\hline $\begin{array}{l}\text { Prosopis strombulifera (Lam.) } \\
\text { Benth. var. strombulifera }\end{array}$ & Retortuño & Curtiente & $?$ & Córdoba (ChS) \\
\hline Prosopis torquata (Cav. ex Lag.) & Tintitaco & Dulces & $\mathrm{Fr}$ & San Luis (ChAS) \\
\hline $\begin{array}{l}\text { DC. } \\
\text { (sub Prosopis adesmioides) }\end{array}$ & & $\begin{array}{l}\text { Camas y ruedas de carros y } \\
\text { carretas }\end{array}$ & $\mathrm{Ta}$ & San Luis (ChAS) \\
\hline Pterogyne nitens Tul. & Viraró & Muebles y remos & $\mathrm{Ta}$ & $\begin{array}{l}\text { Riacho de Oro } \\
\quad(\mathrm{ChH})\end{array}$ \\
\hline (sub P. nitens) & Ibiraró o viraró & Tiñe de violeta & $\mathrm{Ta}$ & Misiones (CMI) \\
\hline (sub Machaerium pseudotipa) & Palo rosa & Muebles & $\mathrm{Ta}$ & Misiones (CMI) \\
\hline & Tipa blanca & $\begin{array}{l}\text { Cajas de carretas, muebles } \\
\text { y mostradores }\end{array}$ & Ta & $\begin{array}{l}\text { Jujuy y Tucumán } \\
\text { (CYC) }\end{array}$ \\
\hline Tipuana tipu (Benth.) Kuntze & Tipa & Curtiente & Co & $\begin{array}{l}\text { Jujuy y Tucumán } \\
\text { (CYC) }\end{array}$ \\
\hline (sub Machaerium tipa) & Tipa amarilla & $\begin{array}{l}\text { Carrocerías de carretas, } \\
\text { talladuras, muebles y yugos }\end{array}$ & $\mathrm{Ta}$ & $\begin{array}{l}\text { Jujuy y Tucumán } \\
\text { CYC) }\end{array}$ \\
\hline \multicolumn{5}{|l|}{ JUGLANDACEAE } \\
\hline & & $\begin{array}{l}\text { Aberturas, muebles, } \\
\text { talladuras y viguetas }\end{array}$ & $\mathrm{Ta}$ & $\begin{array}{l}\text { Catamarca y } \\
\text { Tucumán (CYC) }\end{array}$ \\
\hline \multirow[t]{3}{*}{ Juglans australis Griseb. } & $\begin{array}{l}\text { Nogal } \\
\text { cimarrón }\end{array}$ & Tiñe de castaño y curtiente & Co, Du & $\begin{array}{l}\text { Catamarca, Paclín } \\
\text { y Tucumán (CYC) }\end{array}$ \\
\hline & Nogal & $\begin{array}{l}\text { Construcciones varias y } \\
\text { muebles finos }\end{array}$ & $\mathrm{Ta}$ & Jujuy (CYC) \\
\hline & & Comen su nuez dulce & $\mathrm{Se}$ & Tucumán (CYC) \\
\hline \multicolumn{5}{|l|}{ LAURACEAE } \\
\hline Ocotea diospyrifolia (Meisn.) Mez & Laurel blanco & Muebles & $\mathrm{Ta}$ & Formosa $(\mathrm{ChH})$ \\
\hline \multirow[t]{3}{*}{ (sub Ocotea suaveolens) } & Canela molle & Curtiente & Co & Misiones (CMI) \\
\hline & & Tiñe de violeta oscuro & Du & Catamarca (CYC) \\
\hline & & Curtir pieles finas & Co & Catamarca (CYC) \\
\hline $\begin{array}{l}\text { Ocotea porphyria (Griseb.) van } \\
\text { der Werff }\end{array}$ & Laurel & $\begin{array}{l}\text { Encatrados, muebles y } \\
\text { viguetas }\end{array}$ & $\mathrm{Ta}$ & $\begin{array}{l}\text { Catamarca, Jujuy } \\
\text { y Tucumán (CYC) }\end{array}$ \\
\hline \multirow[t]{3}{*}{ (sub Nectandra porphyria) } & & $\begin{array}{l}\text { Ribeteado de } \\
\text { embarcaciones }\end{array}$ & $\mathrm{Ta}$ & $\begin{array}{l}\text { Riacho de Oro } \\
\text { (ChH) }\end{array}$ \\
\hline & Laurel negro & Curtir pieles finas & Co & Misiones (CMI) \\
\hline & & Tiñe de violeta & $\mathrm{Ta}$ & Misiones (CMI) \\
\hline \multicolumn{5}{|l|}{ LINACEAE } \\
\hline Linum usitatissimum L. & Lino & Textil & $\mathrm{Ta}$ & Mercedes (CPA) \\
\hline \multicolumn{5}{|l|}{ MALVACEAE } \\
\hline Gossypium barbadense* L. & Algodón & Textil & $\mathrm{Se}$ & Misiones (CMI) \\
\hline $\begin{array}{l}\text { Pavonia communis A. St.-Hil. } \\
\text { (sub Pavonia spinifex) }\end{array}$ & Escoba negra & Textil & Ta? & Misiones (CMI) \\
\hline \multicolumn{5}{|l|}{ MELIACEAE } \\
\hline $\begin{array}{l}\text { Cabralea canjerana (Vell.) Mart. } \\
\text { (sub Trichilia canjerana) }\end{array}$ & Cancharana & Curtiente & Co & Misiones (CMI) \\
\hline Cedrela fissilis Vell. & & Muebles y remos & $\mathrm{Ta}$ & Misiones (CMI) \\
\hline (sub Cedrela brasiliensis) & Cedro & $\begin{array}{l}\text { Embarcaciones, muebles, } \\
\text { pisos, puertas y aberturas }\end{array}$ & $\mathrm{Ta}$ & $\begin{array}{l}\text { Tucumán y Jujuy } \\
\text { (CYC) }\end{array}$ \\
\hline $\begin{array}{l}\text { Guarea macrophylla Vahl } \\
\text { (sub Guarea sp.) }\end{array}$ & Cedrillo & Muebles & $\mathrm{Ta}$ & Formosa (ChH) \\
\hline
\end{tabular}




\begin{tabular}{|c|c|c|c|c|}
\hline Nombre científico actualizado & $\begin{array}{c}\text { Nombre } \\
\text { vulgar criollo }\end{array}$ & Aplicación específica & Parte usada & $\begin{array}{l}\text { Localidad } \\
\text { referida y CBCE }\end{array}$ \\
\hline \multirow[t]{2}{*}{ Melia azederach L. } & Paraíso & Culatas de rifles y muebles & $\mathrm{Ta}$ & Tucumán (CYC) \\
\hline & Catiguá & Tiñe de violeta y curtiente & Co & Formosa $(\mathrm{ChH})$ \\
\hline \multirow[t]{2}{*}{ Trichilia catigua A. Juss. } & Catiguá & Cajas de carretas & $\mathrm{Ta}$ & Misiones (CMI) \\
\hline & colorado & $\begin{array}{l}\text { Tiñe de pardo-rojizo y } \\
\text { curtiente }\end{array}$ & Co & Misiones (CMI) \\
\hline Trichilia claussenii C. DC. & Catiguá blanco & Curtiente y para teñir & Co & Misiones (CMI) \\
\hline
\end{tabular}

(sub Trichilia hieronymi)

\section{MORACEAE}

Maclura tinctoria (L.) Steud. subsp. mora (Griseb.) Vázq. Avila

(sub Maclura mora)

\section{MYRTACEAE}

Blepharocalyx salicifolius (Kunth)

O. Berg

(sub Blepharocalyx cisplatensis)

Campomanesia xanthocarpa $\mathrm{O}$.

Berg var. xanthocarpa

(sub Campomanesia crenata)

Eugenia myrcianthes Nied.

(sub Myrcianthes edulis)

(sub Eugenia edulis)
Mora

Arrayán

Guabiroba o Mangos

Guabirá

Eugenia uniflora L.

(sub E. uniflora)

(sub Eugenia michelii)

Pitanga

Myrcianthes mato (Griseb.)

McVaugh

(sub Eugenia mato)

Myrcianthes pungens (O. Berg)

D. Legrand

(sub Eugenia pungens)

Plinia trunciflora (O. Berg) Kausel

(sub Eugenia cauliflora)

Psidium guajava L.

(sub P. guajava)

(sub Psidium guava var. pyriferum)

\section{NYCTAGINACEAE}

Pisonia zapallo Griseb.
Guavirá guazú

Cereza

Iguajai

Arrayán,

arrayán

espinudo

Mato, mato

colorado

Ñangapiry

Vaporití

colorado

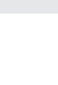

\section{Muebles}

Se comen frescos

Construcciones varias

Se comen frescos y tiñen de violeta

Curtiente y tiñe de rojo

Leña para cocinar y para calefacción, muebles y encatrados

Se comen frescos

Leña para calefacción y muebles

Se comen frescos

Se comen frescos

Guaviyú

Se comen frescos

Ibaponú Se comen frescos

$\mathrm{Fr}$

$\mathrm{Fr}$

$\mathrm{Ta}$

$\mathrm{Fr}$

Ta

$\mathrm{Fr}$

Co

Co
Ta

\section{$\mathrm{Fr}$}

Ta

Ta

$\mathrm{Fr}$

$\mathrm{Fr}$

$\mathrm{Fr}$

$\mathrm{Fr}$

\section{Se comen frescos}

\section{Arazá}

Curtiente
Guayabo
Muebles finos y mazas de $\quad$ Ta carretas

Se comen frescos

Tiñe de amarillo y muebles

Se comen frescos y en dulces

$\begin{array}{ll}\text { Ta } & \begin{array}{l}\text { Riacho de Oro y } \\ \text { Formosa }(\mathrm{ChH})\end{array} \\ \mathrm{Fr} & \text { Formosa }(\mathrm{ChH}) \\ \mathrm{Ta} & \text { Misiones }(\mathrm{CMI})\end{array}$

Misiones (CMI)

Ta $\quad$ Misiones (CMI)

Fr Misiones (CMI)

Ta Misiones (CMI)

$\mathrm{Fr} \quad$ Misiones (CMI)

Ta Catamarca, Jujuy

y Tucumán (CYC)

\section{Catamarca y}

Tucumán (CYC)

Formosa (ChH)

Formosa $(\mathrm{ChH})$

Misiones (CMI)

Misiones (CMI)

Misiones (CMI)

Catamarca, Jujuy

y Tucumán (CYC)

r Catamarca, Jujuy y Tucumán (CYC

Formosa $(\mathrm{ChH})$

Formosa $(\mathrm{ChH})$

$r \quad$ Misiones (CMI)

Catamarca (CYC)

Fr Formosa $(\mathrm{CCH})$

$\mathrm{Fr} \quad$ Misiones (CMI)

Co Misiones (CMI)

Ta Misiones (CMI)

$\mathrm{Ta} \quad$ Formosa $(\mathrm{ChH})$

$\mathrm{Fr} \quad$ Formosa $(\mathrm{ChH})$

Dulces

Cen

Tucumán (CYC) 


\begin{tabular}{|c|c|c|c|c|}
\hline Nombre científico actualizado & $\begin{array}{c}\text { Nombre } \\
\text { vulgar criollo }\end{array}$ & Aplicación específica & Parte usada & $\begin{array}{l}\text { Localidad } \\
\text { referida y CBCE }\end{array}$ \\
\hline & Yuquery buzú & Pulir maderas (abrasivo) & $\mathrm{Ho}$ & Formosa (ChH) \\
\hline \multicolumn{5}{|l|}{ OLACACEAE } \\
\hline & Pata & Curtiente & $\mathrm{Ra}$ & Catamarca (CYC) \\
\hline & $\begin{array}{l}\text { Membrillo } \\
\text { silvestre }\end{array}$ & Tiñe de castaño claro & $\mathrm{Ra}$ & La Pampa (CPA) \\
\hline \multirow[t]{3}{*}{ Ximenia americana L. } & $\begin{array}{l}\text { Abriboquilla } \\
\text { del campo }\end{array}$ & Aguardiente y dulces & $\mathrm{Fr}$ & San Luis (ChAS) \\
\hline & $\begin{array}{l}\text { Albaricoque, } \\
\text { Albaricoquillo }\end{array}$ & $\begin{array}{l}\text { Tiñe de castaño claro y } \\
\text { curtiente }\end{array}$ & $\mathrm{Ra}, \mathrm{Co}$ & $\begin{array}{l}\text { San Luis y Minas } \\
\text { (ChAS) }\end{array}$ \\
\hline & & Muebles finos & $\mathrm{Ta}$ & San Luis (ChAS) \\
\hline \multicolumn{5}{|l|}{ PHYTOLACCACEAE } \\
\hline \multirow[t]{2}{*}{ Phytolacca dioica L. } & Ombú & Lejía para jabón & Cen & Formosa $(\mathrm{ChH})$ \\
\hline & & Lejía para jabón & Cen & Misiones (CMI) \\
\hline \multicolumn{5}{|l|}{ POLYGONACEAE } \\
\hline Ruprechtia apetala Wedd. & Pata & $\begin{array}{l}\text { Arcones, yugos y timones } \\
\text { de carretas }\end{array}$ & $\mathrm{Ta}$ & Catamarca (CYC) \\
\hline $\begin{array}{l}\text { (sub Ruprechtia excelsa) } \\
\text { (sub Ruprechtia corilyfolia) }\end{array}$ & $\begin{array}{l}\text { Manzano del } \\
\text { campo }\end{array}$ & Cucharas de madera & $\mathrm{Ta}$ & $\begin{array}{l}\text { Rio Segundo } \\
\text { (ChS) }\end{array}$ \\
\hline $\begin{array}{l}\text { Ruprechtia laxiflora Meisn. } \\
\text { (sub Ruprechtia vivaru) }\end{array}$ & $\begin{array}{l}\text { Viraro, Viraró } \\
\text { colorado }\end{array}$ & $\begin{array}{l}\text { Arcones, muebles, yugos, } \\
\text { timones y "flechas" de } \\
\text { carretas }\end{array}$ & $\mathrm{Ta}$ & $\begin{array}{l}\text { Catamarca, Jujuy } \\
\text { y Tucumán (CYC) }\end{array}$ \\
\hline \multicolumn{5}{|l|}{ PRIMULACEAE } \\
\hline & Canelón & Lejía para jabón & Cen & Formosa $(\mathrm{ChH})$ \\
\hline $\begin{array}{l}\text { Myrsine laetevirens (Mez) } \\
\text { Arechav. }\end{array}$ & $\begin{array}{l}\text { Capororoca } \\
\text { colorada }\end{array}$ & Curtiente & Co & Misiones (CMI) \\
\hline (sub Myrsine floribunda) & San Antonio & $\begin{array}{l}\text { Construcciones varias, } \\
\text { cajas de carretas, toneles y } \\
\text { duelas de toneles }\end{array}$ & $\mathrm{Ta}$ & $\begin{array}{l}\text { Tucumán y Jujuy } \\
\text { (CYC) }\end{array}$ \\
\hline \multicolumn{5}{|l|}{ RHAMNACEAE } \\
\hline & & $\begin{array}{l}\text { Mangos, mazas y llantas de } \\
\text { ruedas de carros y carretas }\end{array}$ & $\mathrm{Ta}$ & $\begin{array}{l}\text { Catamarca y } \\
\text { Tucumán (CYC) }\end{array}$ \\
\hline & & Se comían frescos y en licor & $\mathrm{Fr}$ & $\begin{array}{l}\text { Catamarca y } \\
\text { Jujuy (CYC) }\end{array}$ \\
\hline \multirow[t]{2}{*}{ Condalia buxifolia Reissek } & & Se preparaba aloja & $\mathrm{Fr}$ & Tucumán (CYC) \\
\hline & Piquillín & Curtiente & Co & Paclín (CYC) \\
\hline \multirow[t]{5}{*}{ (sub Condalia lineata) } & & Mangos y muebles & $\mathrm{Ta}$ & La Pampa (CPA) \\
\hline & & Dulces y en licor & $\mathrm{Fr}$ & La Pampa (CPA) \\
\hline & & $\begin{array}{l}\text { Mangos, muebles, rayos } \\
\text { y llantas de ruedas de } \\
\text { carretas }\end{array}$ & $\mathrm{Ta}$ & San Luis (ChAS) \\
\hline & & Dulces y aguardiente & $\mathrm{Fr}$ & San Luis (ChAS) \\
\hline & & Tiñe de violeta & $\mathrm{Ra}$ & $\begin{array}{l}\text { Catamarca y } \\
\text { Tucumán (CYC) }\end{array}$ \\
\hline Condalia microphylla Cav. & Piquillín & Madera tintórea & $\mathrm{Ta}$ & Jujuy (CYC) \\
\hline \multirow[t]{2}{*}{ (sub Condalia lineata) } & & Tiñe de violeta & $\mathrm{Ra}$ & La Pampa (CPA) \\
\hline & & Tiñe de violeta & $\mathrm{Ra}$ & San Luis (ChAS) \\
\hline \multirow{4}{*}{$\begin{array}{l}\text { Discaria americana Gillies \& Hook. } \\
\text { (sub Discaria longispina) }\end{array}$} & Tala & Quitamanchas & $?$ & Pocho (ChAS) \\
\hline & Mistol & Lavar ropa de lana & Co & Córdoba (ChS) \\
\hline & & $\begin{array}{l}\text { Se comen frescos y se } \\
\text { preparan dulces y aloja }\end{array}$ & $\mathrm{Fr}$ & $\begin{array}{l}\text { Jujuy y Tucumán } \\
\text { (CYC) }\end{array}$ \\
\hline & & $\begin{array}{l}\text { Detergente y tiñe de castaño } \\
\text { claro }\end{array}$ & Co & $\begin{array}{l}\text { Jujuy y Tucumán } \\
\text { (CYC) }\end{array}$ \\
\hline
\end{tabular}




\begin{tabular}{|c|c|c|c|c|}
\hline Nombre científico actualizado & $\begin{array}{c}\text { Nombre } \\
\text { vulgar criollo }\end{array}$ & Aplicación específica & Parte usada & $\begin{array}{l}\text { Localidad } \\
\text { referida y CBCE }\end{array}$ \\
\hline Sarcomphalus mistol (Griseb.) & & Muebles y ejes de carretas & Ta & Tucumán (CYC) \\
\hline Hauenschild & & Ejes de carretas y muebles & $\mathrm{Ta}$ & San Luis (ChAS) \\
\hline \multirow[t]{3}{*}{ (sub Zizyphus mistol) } & & $\begin{array}{l}\text { Se comen frescos y } \\
\text { se elaboran dulces y } \\
\text { aguardiente }\end{array}$ & $\mathrm{Fr}$ & San Luis (ChAS) \\
\hline & & Curtiente & $\mathrm{Ra}$ & San Luis (ChAS) \\
\hline & & $\begin{array}{l}\text { Detergente y tiñe de castaño } \\
\text { claro }\end{array}$ & Co & San Luis (ChAS) \\
\hline Scutia buxifolia Reissek & Coronillo & Tiñe de colorado & Co & Paclín (CYC) \\
\hline \multicolumn{5}{|l|}{ ROSACEAE } \\
\hline Polylepis australis Bitter & Quenua & Leña para calefacción & $\mathrm{Ta}$ & Jujuy (CYC) \\
\hline (sub Polylepis racemosa) & & Papel de cigarrillos & Co & Jujuy (CYC) \\
\hline \multicolumn{5}{|l|}{ RUBIACEAE } \\
\hline Calycophyllum multiflorum Griseb. & Palo blanco & $\begin{array}{l}\text { Cajas de carretas y flechas } \\
\text { de carros }\end{array}$ & $\mathrm{Ta}$ & Tucumán (CYC) \\
\hline Galium hirtum Lam. & Soconte & Tiñe de colorado & $\mathrm{Ta}$ & Jujuy (CYC) \\
\hline (sub Relbunicum hirtum) & Cangai & Tiñe de colorado & $\mathrm{Ra}$ & Misiones (CMI) \\
\hline $\begin{array}{l}\text { Galium richardianum (Gillies ex } \\
\text { Hook. \& Arn.) Endl. ex Walp. var. } \\
\text { richardianum }\end{array}$ & Soconcho & Tiñe de rosado & $\mathrm{Ra}$ & Córdoba (ChS) \\
\hline $\begin{array}{l}\text { (sub G. richardianum) } \\
\text { (sub Galium pusillum) }\end{array}$ & Relfuel & Tiñe de rojo & $?$ & La Pampa (CPA) \\
\hline \multirow[t]{2}{*}{ Galium sp. } & $\begin{array}{l}\text { Rubia o raíz } \\
\text { de teñir }\end{array}$ & $\begin{array}{l}\text { Tiñe de rosado o rojo } \\
\text { carmesí }\end{array}$ & $\mathrm{Ra}$ & $\begin{array}{l}\text { Córdoba y Anejas } \\
\text { Norte (ChS) }\end{array}$ \\
\hline & & $\begin{array}{l}\text { Tiñe de rosado o rojo } \\
\text { carmesí }\end{array}$ & $\mathrm{Ra}$ & Minas (ChAS) \\
\hline \multirow[t]{2}{*}{ Genipa americana L. } & Ñändipá & $\begin{array}{l}\text { Arcones, muebles y cajas } \\
\text { de carretas }\end{array}$ & $\mathrm{Ta}$ & Formosa $(\mathrm{ChH})$ \\
\hline & & $\begin{array}{l}\text { Se comen frescos y tiñen de } \\
\text { azulado }\end{array}$ & $\mathrm{Fr}$ & Formosa $(\mathrm{ChH})$ \\
\hline $\begin{array}{l}\text { Pogonopus tubulosus (A. Rich. ex } \\
\text { DC.) K. Schum. } \\
\text { (sub Pogonopus febrifugus) }\end{array}$ & Quina & Construcciones varias & $\mathrm{Ta}$ & Jujuy (CYC) \\
\hline \multicolumn{5}{|l|}{ RUTACEAE } \\
\hline $\begin{array}{l}\text { Balfourodendron riedelianum } \\
\text { (Engl.) Engl. }\end{array}$ & $\begin{array}{l}\text { Guatambú } \\
\text { blanco }\end{array}$ & $\begin{array}{l}\text { Cepillos, mangos, remos, } \\
\text { toneles y ejes de carretas }\end{array}$ & $\mathrm{Ta}$ & Misiones (CMI) \\
\hline \multirow[t]{2}{*}{$\begin{array}{l}\text { Citrus } \mathrm{x} \text { aurantium } \mathrm{L} \text {. } \\
\text { (sub Citrus vulgaris) }\end{array}$} & $\begin{array}{l}\text { Naranjo } \\
\text { amargo }\end{array}$ & Mangos y ejes de carretas & $\mathrm{Ta}$ & Misiones (CMI) \\
\hline & Naranjo agrio & Ejes de carretas & $\mathrm{Ta}$ & Tucumán (CYC) \\
\hline Esenbeckia febrifuga (A. St.-Hil.) & Naranjillo & Carrocerías de carretas & $\mathrm{Ta}$ & Misiones (CMI) \\
\hline A. Juss. ex Mart. & bravo & Flechas & $\mathrm{Ta}$ & Misiones (CMI) \\
\hline $\begin{array}{l}\text { Zanthoxylon fagara (L.) Sarg. } \\
\text { (sub Zanthoxylon sp.) }\end{array}$ & Cuentrillo & Toneles & $\mathrm{Ta}$ & Misiones (CMI) \\
\hline \multirow{2}{*}{$\begin{array}{l}\text { Zanthoxylon rhoifolium Lam. } \\
\text { (sub Zanthoxylon sp.) }\end{array}$} & Cuentrillo & Toneles & $\mathrm{Ta}$ & Misiones (CMI) \\
\hline & & $\begin{array}{l}\text { Encatrados, mostradores y } \\
\text { muebles }\end{array}$ & $\mathrm{Ta}$ & $\begin{array}{l}\text { Catamarca y } \\
\text { Tucumán (CYC) }\end{array}$ \\
\hline \multirow[t]{3}{*}{$\begin{array}{l}\text { Zanthoxylum coco Gillies ex Hook. } \\
\text { f. \& Arn. }\end{array}$} & & Para teñir y curtiente & Co & $\begin{array}{l}\text { Catamarca y } \\
\text { Tucumán (CYC) }\end{array}$ \\
\hline & Coco & Para teñir & Ho & Catamarca (CYC) \\
\hline & & $\begin{array}{l}\text { Bateas, mostradores y } \\
\text { muebles }\end{array}$ & $\mathrm{Ta}$ & San Luis (ChAS) \\
\hline
\end{tabular}




\begin{tabular}{|c|c|c|c|c|}
\hline Nombre científico actualizado & $\begin{array}{c}\text { Nombre } \\
\text { vulgar criollo }\end{array}$ & Aplicación específica & Parte usada & $\begin{array}{l}\text { Localidad } \\
\text { referida y CBCE }\end{array}$ \\
\hline & & Curtiente & Co & San Luis (ChAS) \\
\hline & & Tiñe de "oscuro" & Ho & San Luis (ChAS) \\
\hline & Cochucho & Puertas y cajas de carretas & $\mathrm{Ta}$ & Jujuy (CYC) \\
\hline \multirow{2}{*}{$\begin{array}{l}\text { Zanthoxylum petiolare A. St.-Hil. } \\
\& \text { Tul. } \\
\text { (sub Zanthoxylum naranjillo) }\end{array}$} & Cunatuná & Muebles y tinajas & $\mathrm{Ta}$ & Formosa $(\mathrm{ChH})$ \\
\hline & Tembetary & Muebles & $\mathrm{Ta}$ & Formosa (ChH) \\
\hline \multirow[t]{3}{*}{ Zanthoxylum sp. } & $\begin{array}{l}\text { Naranjillo del } \\
\text { campo }\end{array}$ & Mangos & $\mathrm{Ta}$ & Jujuy (CYC) \\
\hline & $\begin{array}{l}\text { Tembetary } \\
\text { blanco }\end{array}$ & Cajas de carretas y mangos & $\mathrm{Ta}$ & Misiones (CMI) \\
\hline & Ajicillo & Muebles & $\mathrm{Ta}$ & Tucumán (CYC) \\
\hline \multicolumn{5}{|l|}{ SALICACEAE } \\
\hline & & $\begin{array}{l}\text { Embarcaciones, remos, y } \\
\text { leña para cocinar }\end{array}$ & $\mathrm{Ta}$ & Formosa $(\mathrm{ChH})$ \\
\hline \multirow[t]{3}{*}{ Salix humboldtiana Willd. } & Sauce & Leña para cocinar & $\mathrm{Ta}$ & Jujuy (CYC) \\
\hline & & Tiñe de color rosa y café & Co & Tucumán (CYC) \\
\hline & & $\begin{array}{l}\text { Como combustible y para } \\
\text { embarcaciones }\end{array}$ & $\mathrm{Ta}$ & $\begin{array}{l}\text { Guaymallén } \\
\text { (CUY) }\end{array}$ \\
\hline Xylosma pubescens Griseb. & Coronillo & Para teñir & Co & Tucumán (CYC) \\
\hline \multicolumn{5}{|l|}{ SAPINDACEAE } \\
\hline $\begin{array}{l}\text { Allophylus edulis (A. St.-Hil., A. } \\
\text { Juss. \& Cambess.) Hieron. ex }\end{array}$ & Chal chal & $\begin{array}{l}\text { Se comen frescos y se } \\
\text { elaboran bebidas }\end{array}$ & $\mathrm{Fr}$ & $\begin{array}{l}\text { Catamarca, Jujuy } \\
\text { y Tucumán (CYC) }\end{array}$ \\
\hline Niederl. & & $\begin{array}{l}\text { Muebles rústicos, leña para } \\
\text { cocinar y para calefacción }\end{array}$ & $\mathrm{Ta}$ & $\begin{array}{l}\text { Catamarca, Jujuy } \\
\text { y Tucumán (CYC) }\end{array}$ \\
\hline & Vacú & Se comen frescos & $\mathrm{Fr}$ & Misiones (CMI) \\
\hline $\begin{array}{l}\text { Athyana weinmanniifolia (Griseb.) } \\
\text { Radlk. } \\
\text { (sub Thouinia weinmannifolia) }\end{array}$ & Tarco & Muebles finos & $\mathrm{Ta}$ & Jujuy (CYC) \\
\hline $\begin{array}{l}\text { Cupania vernalis Cambess. } \\
\text { (sub Cupania uruguensis) }\end{array}$ & Camboatá & Para hacer carbón & $\mathrm{Ta}$ & Misiones (CMI) \\
\hline $\begin{array}{l}\text { Diatenopteryx sorbifolia Radlk. } \\
\text { (sub Thouinia ornifolia) }\end{array}$ & María Preta & Muebles & $\mathrm{Ta}$ & Misiones (CMI) \\
\hline \multicolumn{5}{|l|}{ SAPOTACEAE } \\
\hline Chrysophyllum gonocarpum & Aguay miní & Se comen frescos & $\mathrm{Fr}$ & Formosa (ChH) \\
\hline (Mart. \& Eichler) Engl. & & Muebles & $\mathrm{Ta}$ & Formosa $(\mathrm{ChH})$ \\
\hline (sub Chrysophyllum lucumifolium) & Aguay dulce & Se comen frescos & $\mathrm{Fr}$ & Misiones (CMI) \\
\hline $\begin{array}{l}\text { Chrysophyllum marginatum (Hook. } \\
\text { \& Arn.) Radlk. var. marginatum }\end{array}$ & Palo blanco & $\begin{array}{l}\text { Mangos, bastones, cañas y } \\
\text { dinteles }\end{array}$ & $\mathrm{Ta}$ & $\begin{array}{l}\text { Riacho de Oro } \\
\quad(\mathrm{ChH})\end{array}$ \\
\hline (sub Myrsine grisebachii) & Palo de lanza & Muebles & $\mathrm{Ta}$ & Formosa $(\mathrm{ChH})$ \\
\hline $\begin{array}{l}\text { Pouteria salicifolia (Spreng.) Radlk. } \\
\text { (sub Lucuma neriifolia) }\end{array}$ & Aguay guazú & Venenoso & $\mathrm{Fr}$ & Formosa $(\mathrm{ChH})$ \\
\hline $\begin{array}{l}\text { Sideroxylon obtusifolium (Humb. ex } \\
\text { Roem \& Schult.) T. D. Penn. } \\
\text { (sub Bumelia obtusifolia) }\end{array}$ & Horco molle & $\begin{array}{l}\text { Muebles, cajas y carrocerías } \\
\text { de carretas }\end{array}$ & $\mathrm{Ta}$ & $\begin{array}{l}\text { Catamarca y } \\
\text { Tucumán (CYC) }\end{array}$ \\
\hline \multicolumn{5}{|l|}{ SMILACACEAE } \\
\hline Smilax campestris Griseb. & Zarzaparrilla & Tiñe de "azulado" y violeta & $\mathrm{Fr}$ & Misiones (CMI) \\
\hline \multicolumn{5}{|l|}{ SOLANACEAE } \\
\hline Cestrum parqui L'Hér. & Duraznillo & Aviva los colores en tinción & ? & Córdoba (ChS) \\
\hline Grabowskya sp. & Albarillo & Tiñe de anaranjado & $?$ & $\begin{array}{l}\text { Anejos Norte } \\
\text { (ChS) }\end{array}$ \\
\hline
\end{tabular}




\begin{tabular}{|c|c|c|c|c|}
\hline Nombre científico actualizado & $\begin{array}{c}\text { Nombre } \\
\text { vulgar criollo }\end{array}$ & Aplicación específica & Parte usada & $\begin{array}{l}\text { Localidad } \\
\text { referida y CBCE }\end{array}$ \\
\hline $\begin{array}{l}\text { lochroma australe Griseb. } \\
\text { (sub Acnistus australe) }\end{array}$ & Perilla & Muebles & $\mathrm{Ta}$ & Jujuy (CYC) \\
\hline $\begin{array}{l}\text { Vassobia breviflora (Sendtn.) Hunz. } \\
\text { (sub Acnistus breviflora) }\end{array}$ & $\begin{array}{l}\text { Sacha } \\
\text { peral, sacha } \\
\text { membrillo }\end{array}$ & Muebles & $\mathrm{Ta}$ & $\begin{array}{l}\text { Catamarca y } \\
\text { Tucumán (CYC) }\end{array}$ \\
\hline \multicolumn{5}{|l|}{ TILIACEAE } \\
\hline \multirow[t]{2}{*}{ Luehea divaricata Mart. } & $\begin{array}{l}\text { Sotacaballo } \\
\text { blanco }\end{array}$ & Curtiente & $?$ & Misiones (CMI) \\
\hline & & Bateas y cajas de carretas & $\mathrm{Ta}$ & Misiones (CMI) \\
\hline \multirow[t]{2}{*}{ Luehea grandiflora Mart. } & $\begin{array}{l}\text { Sotocaballo } \\
\text { colorado }\end{array}$ & $\begin{array}{l}\text { Bateas, cajas de carretas, } \\
\text { muebles y sillas }\end{array}$ & $\mathrm{Ta}$ & Misiones (CMI) \\
\hline & & Curtiente & Co & Misiones (CMI) \\
\hline \multicolumn{5}{|l|}{ ULMACEAE } \\
\hline $\begin{array}{l}\text { Phyllostylon rhamnoides (J. Poiss.) } \\
\text { Taub. }\end{array}$ & Ibirácatú & $\begin{array}{l}\text { Para hacer "bicheros" y } \\
\text { remos }\end{array}$ & $\mathrm{Ta}$ & Misiones (CMI) \\
\hline \multicolumn{5}{|l|}{ URTICACEAE } \\
\hline $\begin{array}{l}\text { Urera baccifera (L.) Gaudich. ex } \\
\text { Wedd. }\end{array}$ & Ortiga brava & Tejidos rústicos & $\mathrm{Ta}$ & Misiones (CMI) \\
\hline \multicolumn{5}{|l|}{ VERBENACEAE } \\
\hline Lippia sp. & Calamuchina & Tiñe de amarillo & $?$ & Córdoba (ChS) \\
\hline $\begin{array}{l}\text { Vitex megapotamica (Spreng.) } \\
\text { Moldenke } \\
\text { (sub Vitex montevidensis) }\end{array}$ & Tarumá & Se comen frescos & $\mathrm{Fr}$ & Formosa $(\mathrm{ChH})$ \\
\hline \multicolumn{5}{|l|}{ WINTERACEAE } \\
\hline $\begin{array}{l}\text { Drimys winterii J. R. Forst. \& G. } \\
\text { Forst. }\end{array}$ & Magnolia & Construcciones varias & $\mathrm{Ta}$ & Ushuaia (s/a) \\
\hline \multicolumn{5}{|l|}{ ZYGOPHYLLACEAE } \\
\hline Bulnesia bonariensis Griseb. & Guacho & Para lavar ropa de lana & $\mathrm{Ra}$ & Córdoba (ChS) \\
\hline $\begin{array}{l}\text { Bulnesia retama (Gillies ex Hook. \& } \\
\text { Arn.) Griseb. }\end{array}$ & Retamo & $\begin{array}{l}\text { Muebles, postes, leña para } \\
\text { cocinar y para hacer carbón }\end{array}$ & $\mathrm{Ta}$ & San Luis (ChAS) \\
\hline Larrea divaricata Cav. & Jarilla & Tiñe de verde & Tah & Tucumán (CYC) \\
\hline $\begin{array}{l}\text { Porlieria microphylla (Baill.) } \\
\text { Descole, O’Donell \& Lourteig }\end{array}$ & Guayacán & Mangos & $\mathrm{Ta}$ & $\begin{array}{l}\text { Rio Segundo } \\
\text { (ChS) }\end{array}$ \\
\hline (sub Porliera hygrometrica) & & Tiñe de amarillo & ? & Pocho (ChAS) \\
\hline
\end{tabular}

Referencias: *: Cultivada. To: Toda la planta, Ta: Tallo, Tah: Parte aérea, Se: Semilla, Ho: Hoja, Co: Corteza, Fr: Fruto, Du: Duramen, Res: Resina; Ra: Raíz, Fl: Flor, Me: Meristema apical; Cen: Cenizas de parte aérea. Valles Subandinos "Yungas-Chaco" (CYC); Criollos del Chaco Árido y Serrano (ChAS); Criollos del Chaco Seco (ChS); Criollos de Misiones (CMI); Criollos de la región pampeana (CPA); adscripción sin determinar (s/d). Criollos de Cuyo (CUY); Criollos del Chaco Húmedo (ChH).

\section{Discusión}

Entre las categorías de uso no medicinales citadas se destaca la valoración especial que ciertas aplicaciones de las plantas poseían hacia finales del siglo XIX. En efecto, acorde a este momento histórico, se observa la importancia que estas tenían en la construcción de viviendas ("ranchos"), vehículos de transporte y carga (carretas, carros y embarcaciones); en la confección de casi la totalidad de su mobiliario, de sus implementos de labranza, como tintes naturales, utensilios de uso cotidiano, así como la gran valoración de las especies curtientes derivada del papel descollante que tenía por entonces la utilización del cuero (tanto de animales de cría como de la fauna silvestre), importancia que entre los criollos argentinos ha sido especialmente destacada por Sarmiento ([1845] 2000) al caracterizar a estos grupos humanos como verdaderas "civilizaciones del cuero". 


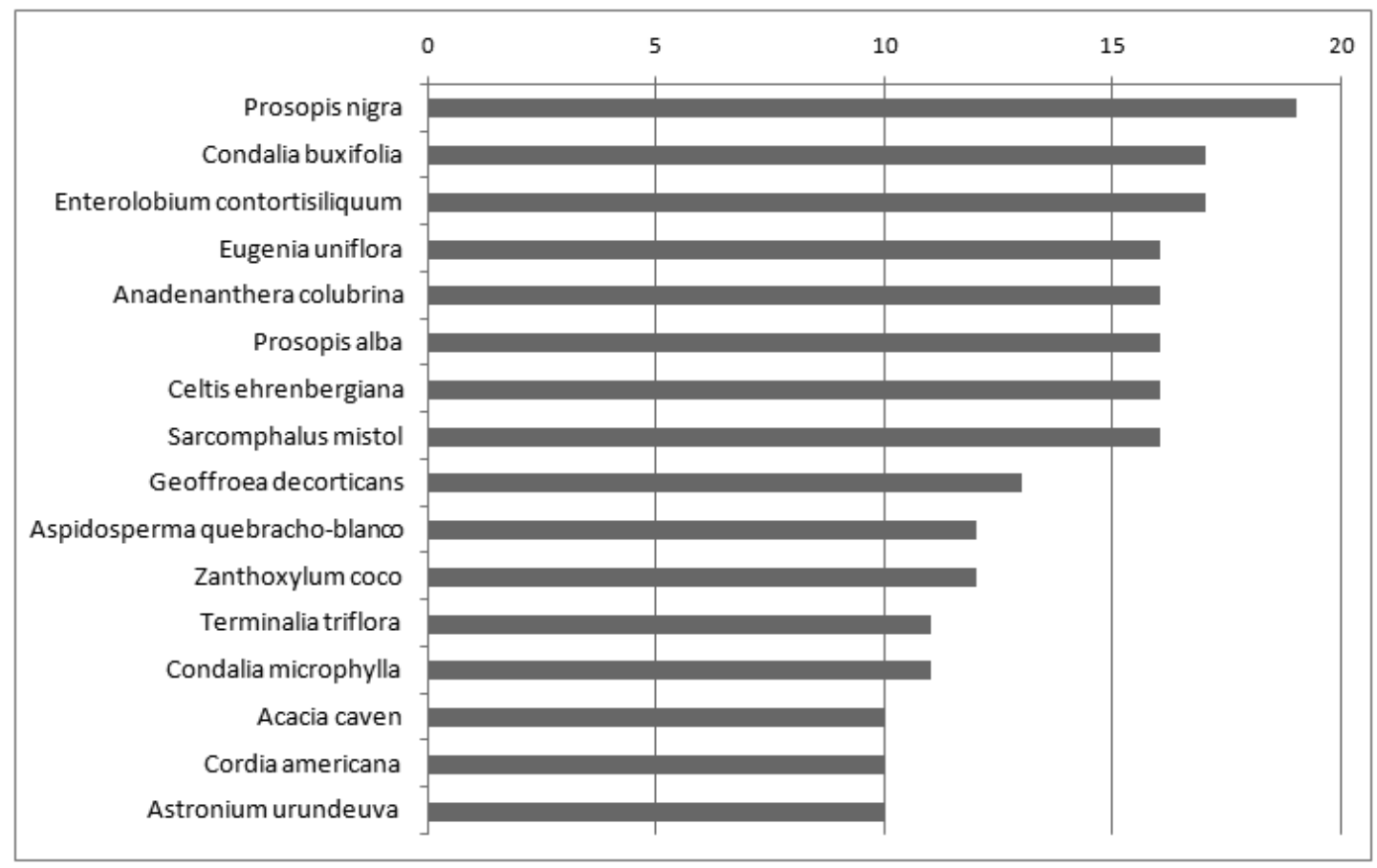

Fig. 1. Principales especies con usos no medicinales.

Fig. 1. Main plant species with non-medicinal uses.

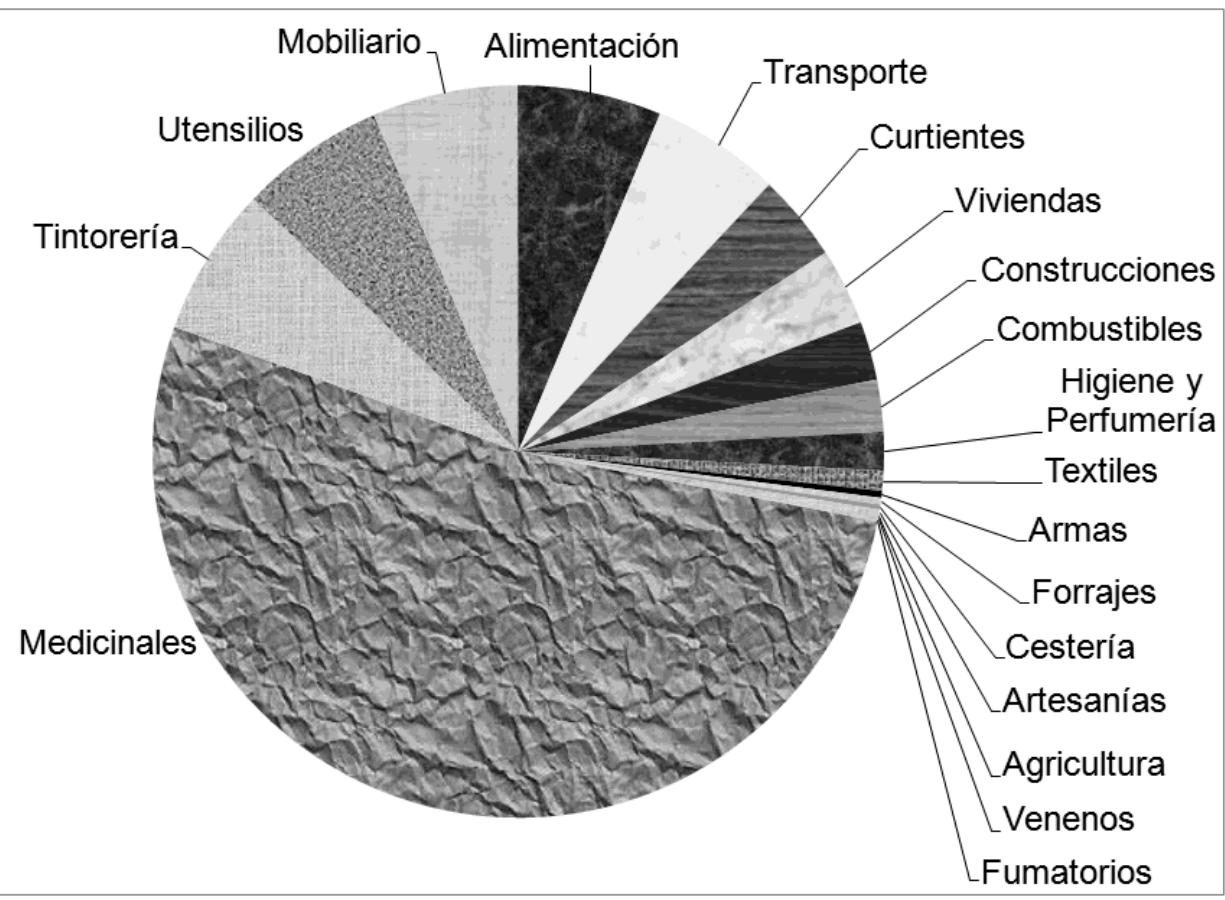

Fig. 2. Cantidad de datos por categorías de usos medicinales y no medicinales.

Fig. 2. Number of data per medicinal and non-medicinal uses. 


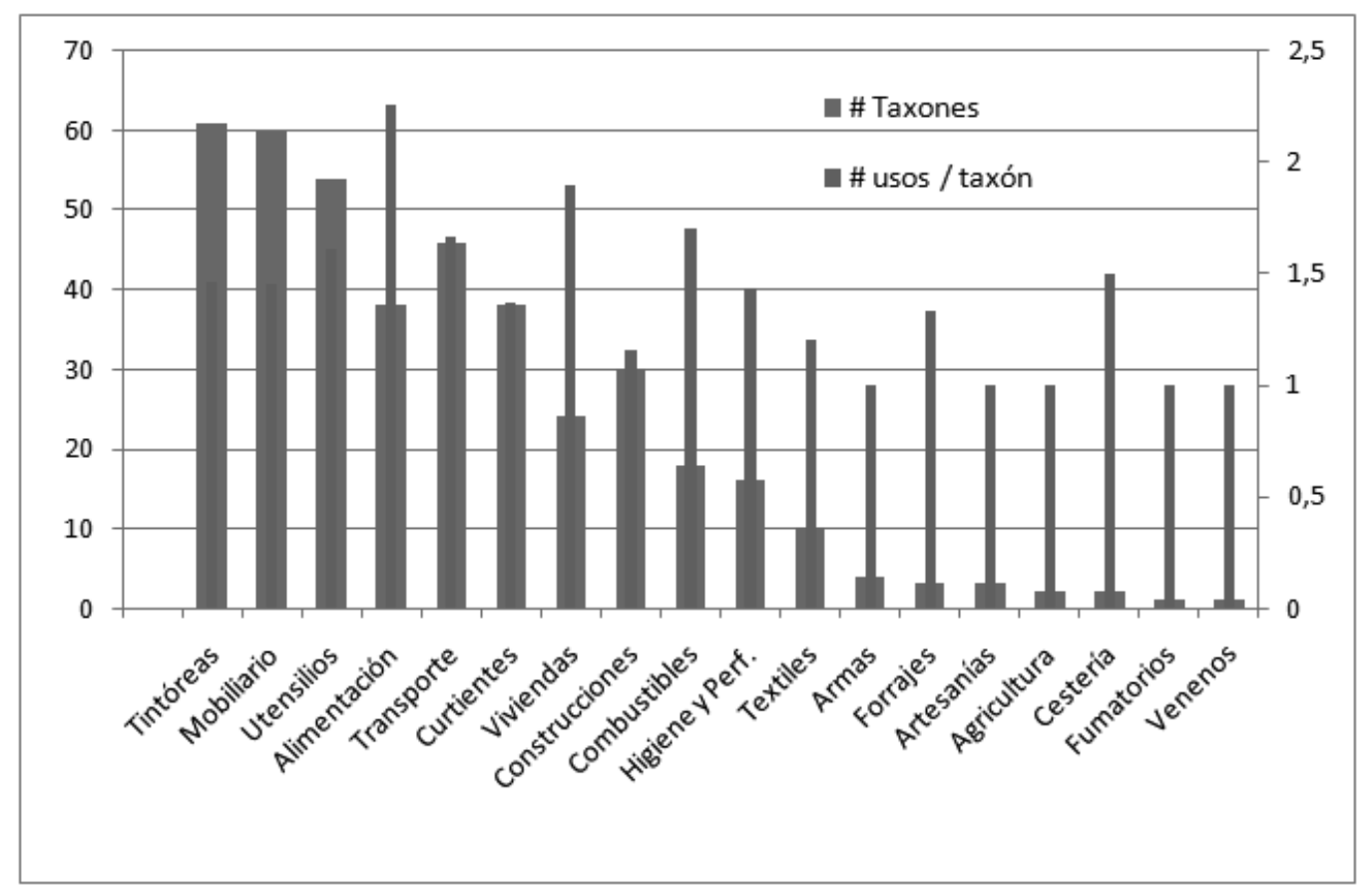

Fig. 3. Cantidad de taxones y de usos por taxón por subcategorías de usos no medicinales.

Fig. 3. Number of taxa and uses per taxa for each sub-category of non-medicinal uses.

Resulta destacable tanto la cantidad de especies utilizadas para teñir (61 taxones) como la diversidad de colores que estas rinden según los datos referidos en la EUP de 1889, ya que su número es sustancialmente superior al registrado entre los criollos del norte argentino hasta la fecha en los trabajos etnobotánicos de Stramiglioli (2007), Palacio et al. (2007) y Trillo et al. (2007). Según estos autores, la gama de colores naturales más frecuentemente registrada corresponde a distintas tonalidades del marrón, amarillo, anaranjado y verde, la cual es mucho más reducida que la obtenida durante la época previa a la aparición de las anilinas. En este sentido, Stramiglioli (2007) admite que se han perdido fuentes naturales del color rojo y del azul, tales como la "grana" y el "añil". De la bibliografía antes mencionada, solo esta última autora cita plantas nativas utilizadas como fuentes del color azul: Indigofera suffruticosa Mill. e I. kurtzii Harms. Éstas eran empleadas a manera de sucedáneos del añil (I. tinctoria L.) cuando este dejó de comercializarse en nuestro país, para ser finalmente reemplazadas por la anilina industrial de dicho color. Por estas razones, la gran cantidad de taxones rescatados del catálogo de la EUP de 1889 como fuentes de extracción de tintes violáceos (11) y azulados (4) resulta altamente ponderable, no solo por su propia originalidad, derivada de haber sido registrados previamente a la aparición de las anilinas, sino por el potencial utilitario que los mismos revisten a futuro. Entre aquellos que brindarían una coloración azulada se cita la parte aérea del "iribú retimá" (Chromolaena laevigata (Lam.) R. M. King \& H. Rob., Asteraceae) y los frutos de la "zarzaparrilla" (Smilax campestris Griseb., Smilacaceae) para los criollos de la provincia de Misiones, así como los frutos del "ñandipá" (Genipa americana L., Rubiaceae) para los criollos del Chaco Húmedo (Formosa). En el detallado estudio de Marzocca (1959) solo se cita el uso tintóreo de esta última especie para indígenas del Chaco Boreal (Guaná, Mbayá y Chamacoco), mientras que explicita que entre las "tribus sureñas" tal color se obtenía solamente con carbón de leña. Respecto a las fuentes del color violáceo, ninguna de las fuentes antes mencionadas (Marzocca, 1959; Palacio et al., 2007; Trillo et al., 2007; 
Tabla 2. Cantidad de datos por aplicación específica.

Table 2. Number of data per specific applications.

\begin{tabular}{|c|c|c|c|c|c|}
\hline Categoría de uso & Aplicación específica & Frec. & $\begin{array}{c}\text { Categoría de } \\
\text { uso }\end{array}$ & Aplicación específica & Frec. \\
\hline \multirow[t]{2}{*}{ AGRICULTURA } & Cultígenos & 1 & & Mazas de carretas & 6 \\
\hline & Arado de palo & 1 & & Remos & 6 \\
\hline \multirow[t]{14}{*}{ ALIMENTACIÓN } & Fresco & 40 & & "Flechas" de carros & 2 \\
\hline & Dulces & 15 & & Ejes de carretillas & 1 \\
\hline & Bebidas alcohólicas & 10 & & $\begin{array}{l}\text { Ribeteado de } \\
\text { embarcaciones }\end{array}$ & 1 \\
\hline & Bebidas & 5 & & Ejes de carretillas & 1 \\
\hline & Añapa & 3 & MOBILIARIO & Muebles & 68 \\
\hline & Aloja & 4 & & Muebles finos & 5 \\
\hline & Hervido & 2 & & Muebles rústicos & 3 \\
\hline & Almidón & 2 & & Sillas & 3 \\
\hline & Patay & 1 & & Arcones & 3 \\
\hline & Tostado & 1 & & Mostradores & 3 \\
\hline & Arrope & 1 & & Camas & 2 \\
\hline & Aceite & 1 & $\begin{array}{l}\text { HIGIENE Y } \\
\text { PERFUMERÍA }\end{array}$ & Jabones (lejías y otros) & 9 \\
\hline & Asado & 1 & & Detergente & 8 \\
\hline & Bolanchao & 1 & & Aromatizante ambientes & 2 \\
\hline \multirow[t]{3}{*}{ ARMAS } & Arcos de flechas & 2 & & Perfumería & 2 \\
\hline & Flechas & 1 & & Algodón sedoso & 1 \\
\hline & Veneno para flechas & 1 & & Quitamanchas & 1 \\
\hline ARTESANÍAS & Talladuras & 3 & TEXTILES & Textil & 4 \\
\hline \multirow[t]{2}{*}{ CESTERÍA } & Trenzados & 2 & & Tejidos rústicos & 3 \\
\hline & Abanicos & 1 & & Algodón & 2 \\
\hline \multirow[t]{4}{*}{ COMBUSTIBLES } & Leña para calefacción & 14 & & Cestería & 1 \\
\hline & Leña para cocinar & 10 & & Cuerdas & 1 \\
\hline & Para hacer carbón & 6 & & Hilado y tejido & 1 \\
\hline & Leña de calidad & 1 & & Sacos o bolsas & 1 \\
\hline \multirow[t]{4}{*}{ CONSTRUCCIÓN } & Postes y pilares & 15 & TINTORERÍA & Color amarillo & 14 \\
\hline & Armazones y encatrados & 14 & & Color violeta & 11 \\
\hline & Viguetas & 5 & & "Para teñir" & 10 \\
\hline & Cercos ganaderos & 1 & & Color castaño claro & 9 \\
\hline \multirow[t]{2}{*}{ CURTIENTES } & Curtiente & 50 & & Color rojo & 9 \\
\hline & Para "pieles finas" & 2 & & Color negro & 6 \\
\hline FORRAJES & Ganado & 4 & & Color verde & 6 \\
\hline FUMATORIOS & Papel de cigarrillos & 1 & & Color rosado & 5 \\
\hline \multirow{5}{*}{$\begin{array}{l}\text { MEDIOS DE } \\
\text { TRANSPORTE }\end{array}$} & Cajas de carretas & 20 & & Color "azulado" & 4 \\
\hline & Ejes de carros y carretas & 13 & & Color rojo carmesí & 3 \\
\hline & Embarcaciones & 11 & & Color anaranjado & 3 \\
\hline & Carrocería de carretas & 9 & & Color gris & 2 \\
\hline & $\begin{array}{l}\text { Ruedas de carros y } \\
\text { carretas }\end{array}$ & 8 & & Color pardo-rojizo & 2 \\
\hline
\end{tabular}




\begin{tabular}{|c|c|c|c|c|c|}
\hline Categoría de uso & Aplicación específica & Frec. & $\begin{array}{c}\text { Categoría de } \\
\text { uso }\end{array}$ & Aplicación específica & Frec. \\
\hline & & & & Color castaño oscuro & 2 \\
\hline & Color "oscuro" & 1 & & Almohadillas & 1 \\
\hline & Tinta para escribir & 1 & & Duelas de toneles & 1 \\
\hline & $\begin{array}{l}\text { Aumentar la intensidad } \\
\text { de los colores }\end{array}$ & 1 & & Abrasivo & 1 \\
\hline \multirow[t]{15}{*}{ UTENSILIOS } & $\begin{array}{l}\text { Mangos herramientas y } \\
\text { cuchillos }\end{array}$ & 29 & & Pabilos & 1 \\
\hline & Toneles & 11 & & Bicheros & 1 \\
\hline & Yugos de arados & 9 & & Goma de pegar & 1 \\
\hline & Bateas & 8 & & Cucharas de madera & 1 \\
\hline & Culatas de rifles & 3 & & Platos y bandejas & 1 \\
\hline & Tinajas & 3 & & & \\
\hline & Bastones y cañas & & VENENOS & Venenos & 1 \\
\hline & Cepillos & 2 & VIVIENDAS & Vigas y viguetas & 12 \\
\hline & Látigos & 2 & & Aberturas & 15 \\
\hline & & & & Pilares & 7 \\
\hline & Cuerdas & 2 & & Encatrados & 7 \\
\hline & Pértigas & 2 & & Dinteles & 1 \\
\hline & Poleas & 2 & & Pisos & 1 \\
\hline & Picas & 1 & & Cielorrasos & 1 \\
\hline & Palas & 1 & & Techumbres & 1 \\
\hline
\end{tabular}

Stramiglioli, 207), cita planta tintórea alguna, a excepción de Demaio et al. (2002) quienes señalan que los frutos y corteza de Condalia buxifolia rinden un color punzó, que podría haberse homologado a dicho color (variando la concentración de la decocción a la que son sometidas tales partes durante la extracción del principio tintóreo). En cambio, en la EUP de 1889, se refieren como tales al duramen del "urundel" (Astronium urundeuva (Allemâo) Engl.), del "viraró" (Pterogyne nitens Tul.) y de la "cañafístula" (Peltophorum dubium (Spreng.) Taub.), así como a los frutos de la "pitanga" (Eugenia uniflora L.) y de la "zarzaparrilla" (Smilax campestris) para criollos de la provincia de Misiones, así como del duramen del "laurel negro" (Ocotea porphyria (Griseb.) van der Werff) para los criollos de Valles Subandinos Yungas-Chaco (Catamarca) y de la provincia de Misiones; la raíz del "piquillín" (Condalia microphylla Cav.) para los criollos de la Pampa (provincia de La Pampa), del Chaco Árido y Serrano (San Luis) y de los Valles Subandinos YungasChaco (Catamarca y Tucumán). El dato de la extracción de tinte violáceo de la corteza de Trichilia catigua A. Juss. por parte de los criollos del Chaco Húmedo tendría carácter dudoso, ya que para los criollos de Misiones es referido el color "pardo-rojizo" para la misma parte de la misma especie. El autor desconoce que estas aplicaciones de las plantas hayan sido informadas alguna vez en publicaciones científicas hasta la fecha para grupos criollos de la Argentina, razón por lo cual se considera prima facie como novedosas para nuestro país.

La elevada cantidad de datos etnobotánicos referidos por la EUP de 1889 respecto a la construcción de viviendas, confección de mobiliario, utensilios domésticos, útiles de labranza y a los combustibles, resulta comparable con la señalada oportunamente por Scarpa (2012a) para los criollos del Chaco Semiárido argentino. Exceptuando 


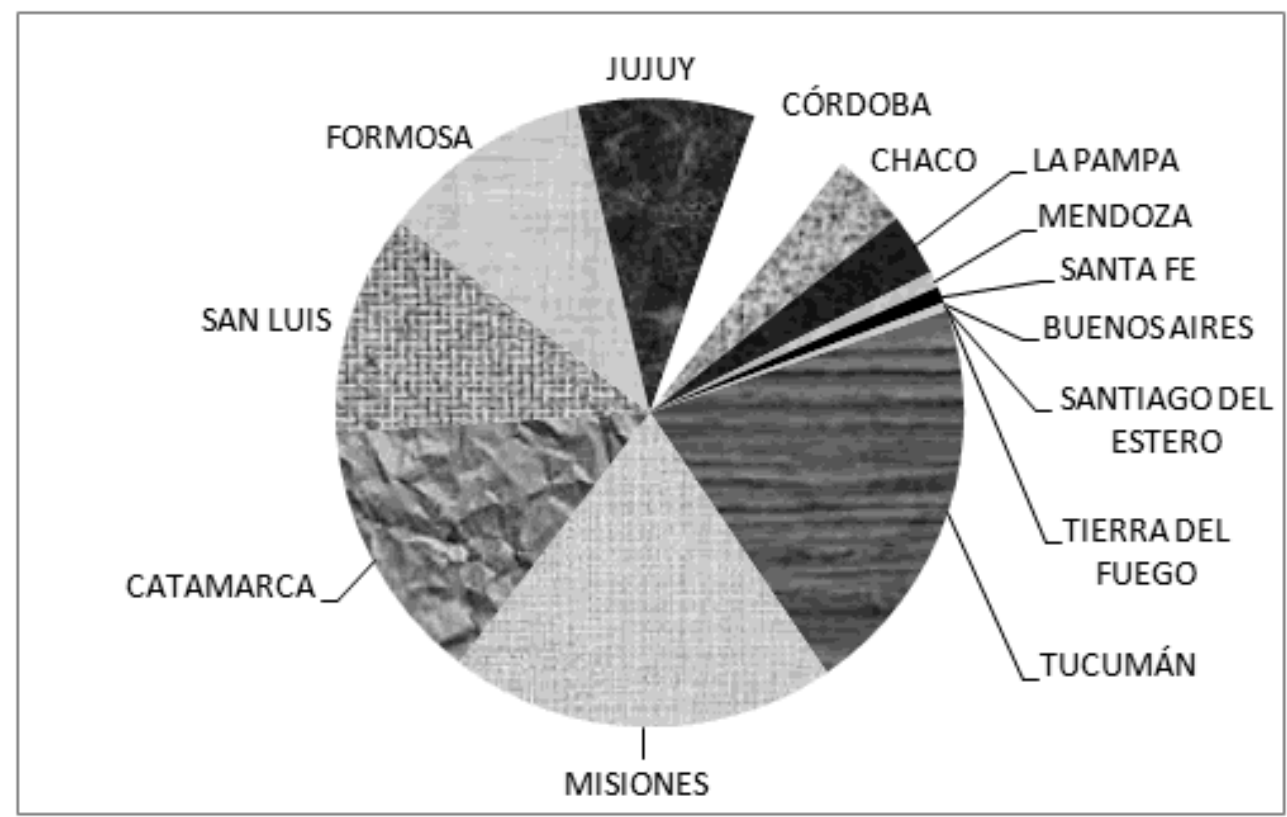

Fig. 4. Cantidad y proporción de usos no medicinales por provincia.

Fig. 4. Number and proportion of non-medicinal uses per province.

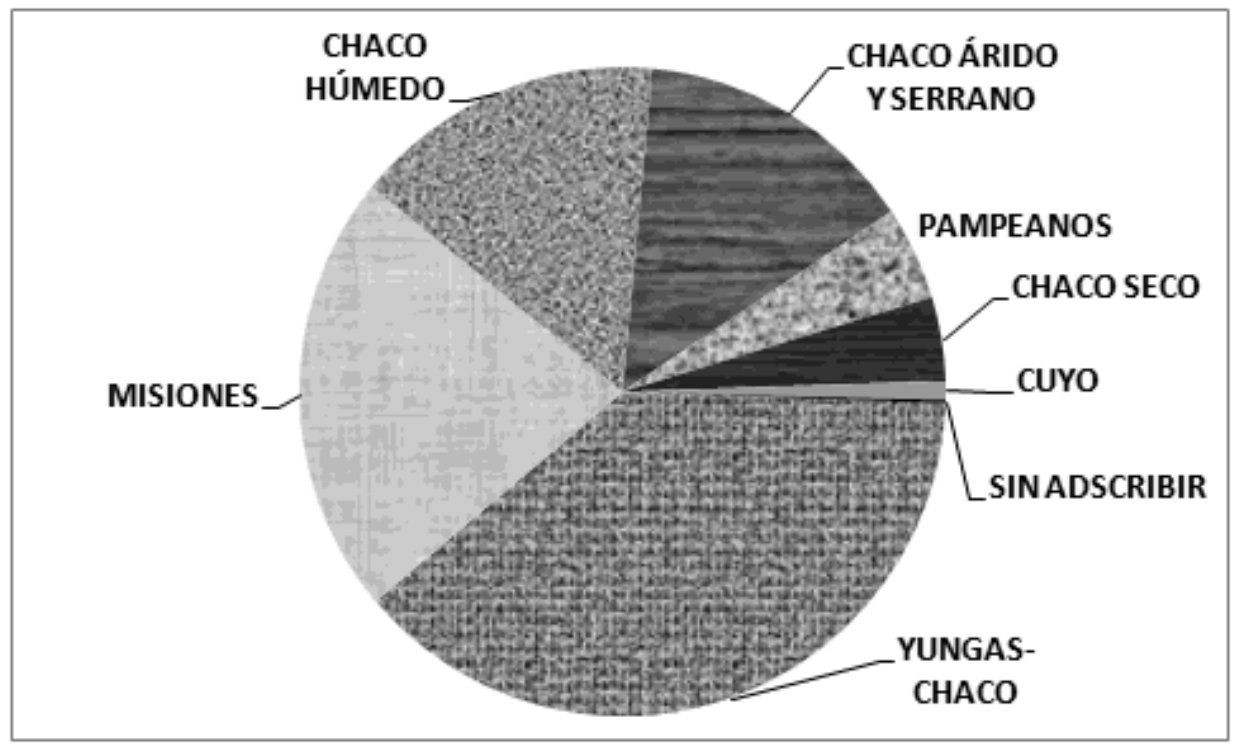

Fig. 5. Cantidad y proporción de usos no medicinales por complejo bio-cultural criollo.

Fig. 5. Number and proportion of non-medicinal uses per criollos bio-cultural complex.

estas últimas, sin embargo, dichas referencias resultan ciertamente originales debido a la rareza de trabajos publicados que describan estas categorías de datos etnobotánicos para criollos de nuestro país en su preciso contexto cultural de referencia.

Por otra parte, también resulta destacable la gran diversidad de taxones y de tipos de 
aplicaciones referidas para la construcción de medios de transporte (carros, carretas y carretillas) que fueron, durante cerca de tres siglos, los únicos vehículos disponibles para la movilización de personas y de mercancías a lo largo y ancho de nuestro territorio, antes de ser reemplazados por camiones y ómnibus. La gran cantidad y diversidad de datos (78) referidos a numerosos taxones vegetales (46) empleados para la confección de cada una de las diferentes piezas constitutivas de estos antiguos medios de transporte (incluidas las embarcaciones, ver la Tabla 2), resultan totalmente novedosas e inéditas para la etnobotánica de nuestro país, debido a la inexistencia de trabajos que aborden esta temática. La gran cantidad de datos etnobotánicos para la categoría Mobiliario (70) asignados a un máximo número de taxones (62) para una misma aplicación específica, también resulta digna de mención.

Respecto al empleo alimentario de las plantas merecen destacarse los usos inéditos de las flores tostadas del "ceibo" (Erythrina cristagalli L.) para los criollos de Valles Subandinos Yungas-Chaco (Jujuy), así como el consumo de los frutos frescos del "ñandipá" (Genipa americana L.) para los del Chaco Húmedo (Formosa). Los usos asignados a esta última especie en mueblería (arcones y muebles) y en cajas de carretas también serían novedosos para nuestro país.

Por último, si bien las propiedades textiles de especies nativas tales como Trema micrantha (L.) Blume (Celtidaceae), Pavonia communis A. St.-Hil. (Malvaceae) y Urera baccifera (L.) Gaudich. (Urticaceae) son citadas por Luna Ercilla (1977) desde el punto de vista botánicoeconómico, esta sería la primera vez que estas lo son desde la perspectiva etnobotánica, es decir, al referirse sus aplicaciones específicas ("tejidos rústicos") en su respectiva adscripción cultural estimada ("criollos de la provincia de Misiones").

Entre las plantas con mayor cantidad de usos no medicinales referidos en el catálogo de la EUP de 1889 (Fig. 1) se citan árboles de reconocida utilización por criollos de varias zonas del país, como Prosopis alba, P. nigra. Enterolobium contortisiliquum, Geoffroea decorticans (Gillies ex Hook. \& Arn.) Burkart, Sarcomphalus mistol, Zanthoxylon coco y Eugenia uniflora, entre otros. Sin embargo, también se destacan entre estos últimos otros cuya versatilidad de empleo no resulta tan difundida en la actualidad, como Condalia buxifolia (con 17 datos), Celtis ehrenbergiana (16) y Acacia caven (Molina) Molina (10 datos) con cantidades de usos sustancialmente elevadas.

La precisión de la estimación efectuada acerca de la adscripción cultural criolla de estos usos queda evidenciada al tener en cuenta los tipos de aplicaciones particulares de las plantas. Ejemplo de ello son los bienes culturales típicamente criollos (ver Scarpa, 2012a) referidos como "bolanchao" (bolillas elaborados con frutos de "mistol" molidos y espolvoreadas con harina de algarroba o de maíz); "patay" (torta seca y chata confeccionada con harina de algarroba apelmazada en molde circular y horneada); "añapa" (bebida resultante de filtrar el macerado en agua de frutos de algarroba molidos), "aloja" (bebida alcohólica resultante de la fermentación de la añapa); "sillas"; "muebles", "carretas" y "toneles", entre otros. Sin embargo, son referidos en el catálogo en cuestión cuatro usos referidos como "flechas", "arcos de flechas" y "veneno para flechas", los cuales constituirían claramente conocimientos criollos sobre usos indígenas de las plantas, con carácter de excepcionalidad.

Los datos etnobotánicos no medicinales rescatados del catálogo de la EUP de 1889 se hallarían claramente sesgados desde la perspectiva etnobotánica, si los comparamos con aquellos provenientes de otras investigaciones de este tipo con criollos argentinos. En primer lugar, se aprecia una sobreestimación de los usos y significados de las plantas de neto corte economicista, que no tiene en cuenta su participación en la simbología religiosa ni en las creencias de los pueblos, entre otros aspectos, de máximo valor según resultados preliminares de investigaciones sobre etnobotánica histórica de criollos del Chaco Húmedo a inicios del siglo XX (Scarpa \& Rosso, inédito). En segunda instancia, la baja valoración de los forrajes silvestres, y de la ganadería misma, que se tenía hacia finales del siglo XIX por quienes organizaron la obtención de estos datos, sería la razón de su escasísima cantidad registrada para este ítem (4). Este desajuste sería ostensible teniendo en cuenta que la mayoría 
de los criollos consultados en ese entonces practicaban una ganadería tradicional en la cual los forrajes, según resultados de investigaciones etnobotánicas actuales con ganaderos criollos (Scarpa, 2007; Muiño, 2010), resultan de una máxima valoración. Ambos sesgos identificados habrían obedecido a que la finalidad del registro y exhibición de estos datos en la EUP de 1889 consistía en atraer productores agrícolas e inversores europeos hacia nuestro país, según las políticas propias de la élite gobernante de la Argentina entre 1880 y 1916, conocida como la "Generación del '80". Es decir, que el criterio de selección de los datos etnobotánicos para dicha exposición habría sido el de maximizar la exhibición de las potencialidades económicas, de tipo agrario-industrialista, que poseían los recursos naturales renovables vegetales de la Argentina, más que transmitir la valoración o significación que los criollos argentinos de ese entonces tenían de las plantas (criterio etnobotánico).

Por último, se comprueba que la proporción de datos para cada complejo bio-cultural estimado resultó similar a la hallada para los datos medicinales de la EUP de 1889 (Scarpa et al., 2016), es decir, valores máximos para los criollos de Valles Subandinos, seguidos por los criollos de Misiones, del Chaco Árido y Serrano, del Chaco Seco y de los Pampeanos. Se destaca que para los dos primeros grupos criollos mencionados, así como para los del Chaco Húmedo (Formosa y Riacho de Oro, provincia del Chaco), todavía no existen investigaciones etnobotánicas exhaustivas, lo cual, teniendo en cuenta la gran cantidad de datos aquí presentados para cada uno de ellos (148, 142 y 100, respectivamente), realza el valor de la presente contribución.

\section{Conclusiones}

Se concluye que, entre los datos no medicinales aquí presentados y los medicinales publicados por Scarpa et al. (2016), se describen, ponen en valor y se analizan según su adscripción bio-cultural específica estimada un total de 1349 datos etnobotánicos exhibidos por el Gobierno de la Nación Argentina ante la Exposición Universal de París de 1889.
La gran cantidad y diversidad de información rescatada como datos etnobotánicos referidos a numerosas categorías de uso y aplicaciones específicas de las plantas para varios complejos bio-culturales criollos de la Argentina, permiten afirmar de modo concluyente el alto valor que posee el análisis de fuentes históricas desde la perspectiva de la etnobotánica actual. Su valor se incrementa aún más al considerar que muchos de ellos resultan novedosos o infrecuentes en la literatura etnobotánica de nuestro país, ya sea por referirse a categorías o usos poco relevados, o bien a grupos criollos cuya relación con las plantas todavía nos resulta incompleta o casi desconocida. Por último, se pone de relieve el alto valor histórico de los datos aquí compilados, en cuanto a su contribución al patrimonio material e inmaterial de los criollos considerados, así como su aporte a la comprensión de procesos históricos asociados a la conformación de sus respectivos acervos etnobotánicos y culturales.

\section{Agradecimientos}

A la Dra. Cintia Rosso, por facilitarme bibliografía aquí citada. Al Consejo Nacional de Investigaciones Científicas y Técnicas (CONICET).

\section{Bibliografía}

ANCONATANI, L. M. \& G. F. SCARPA. 2015. Etnobotánica histórica de las Misiones Franciscanas del este de Formosa I: Hallazgos documentales de fuentes primarias, análisis crítico y comparación con la obra "Erbe medicinali del Chaco" de Franzè (1925). Dominguezia 31: 49-61.

ARENAS, P. 1997. Las fuentes actuales y del pasado para la etnobotánica del Gran Chaco. Monograf. Jard. Bot. Córdoba 5: 17-25.

DEMAIO, P., U. O. KARLIN \& M. MEDINA. 2002. Árboles nativos del centro de Argentina. L.O.L.A., Buenos Aires. 210 pp.

DEPARTAMENTO DE AGRICULTURA DE LA NACIÓN ARGENTINA. 1888. Bol. Depto. Agric. 12. Buenos Aires.

FLORA ARGENTINA. 2015. Base de datos "Flora Argentina”. Instituto de Botánica Darwinion http:// www.floraargentina.edu.ar/ [Consulta: enero-abril 2017]. 
KELlER H. A. \& H. F. ROMERO. 2006. Plantas medicinales utilizadas por campesinos del área de influencia de la Reserva de Biósfera Yabotí (Misiones, Argentina). Bonplandia 15: 125-141.

LUNA ERCILLA, C. A. 1977. Plantas Textiles Indígenas. Fascículo 18-2 del Tomo 2 de la Enciclopedia Argentina de Agricultura y Jardinería. Acme, Buenos Aires.

MARTÍNEZ CROVETTO, R. N. 1963. Las noticias etnobotánicas de Augusto Guinnard. Memorias del Primer Congreso del Área Araucana Argentina, Tomo 2, pp. 29-41. Buenos Aires.

MARTÍNEZ CROVETTO, R. N. 2014†. Algunos datos sobre etnobotánica mocoví. Bonplandia 23: 119-131.

MARZOCCA, A. 1959. Historia de plantas tintóreas y curtientes. Colección Agropecuaria vol. 1. INTA, Buenos Aires. 234 pp.

MEDEIROS, N. H. 2009. Etnobotânica Histórica: Princípios e Procedimientos. NUPEEA/Sociedad Brasileira de Etnobiología e Etnoecología, Recife. 83 pp.

MONTANI, M. C. \& G. F. SCARPA. 2016. Recursos vegetales y prácticas alimentarias entre indígenas Tapiete del noreste de la provincia de Salta, Argentina. Darwiniana Nueva Serie 4: 12-30.

MOREAU, D. 2006. Valorisation de l'usage des plantes medicinales dans la province Misiones (Argentina): exploration d'une alternative de conservation de la foret atlantique. Memoire pour le Diplome Universitaire d'Études Compléméntaire en Ethnobotanique. Universidad de Lille, Francia.

MUIÑO, W. 2010. Ethnobotanical study of the rural population of the West of the Pampa Plain (Argentina). Ethnobotany Research \& Applications 8: 219-231.

NIEDERLEIN, G. 1890. La riqueza forestal de la República Argentina en la Exposición Universal de París de 1889. En ALCORTA, S. (comp.), La República Argentina en la exposición universal de Paris de 1889, tomo 2, pp. 1-102. Mouillot, Paris.

PALACIO, M. O., E. del VALLE CARRIZO \& L. D. ROIC. 2007. Relevamiento del uso de plantas tintóreas en localidades del Departamento Atamisqui (Santiago del Estero, República Argentina). Kurtziana 33: 73-78.

QUEIREL, J. 1897. Misiones. Editorial Penitenciaría Nacional, Buenos Aires.

ROSSO, C. N. 2012. La etnobotánica de los grupos mocovíes de la reducción de San Javier, en el Gran Chaco, durante el siglo XVIII. Tesis Doctoral. Facultad de Filosofía y Letras, Universidad de Buenos Aires. 306 pp.

ROSSO, C. \& G. F. SCARPA. 2012. Identificaciones botánicas de las plantas empleadas entre los mocovíes en la reducción San Javier durante el siglo XVIII a partir de la obra de Florián Paucke, S. J. En ARENAS, P. (ed.), Etnobotánica en zonas áridas y semiáridas del Cono Sur de Sudamérica, pp. 45-70. Sigma, Buenos Aires.

SARMIENTO, D. F. [1845] 2000. Facundo. Civilización y barbarie. Colihue, Buenos Aires. 328 pp.

SCARPA, G. F. 2007. Etnobotánica de los Criollos del oeste de Formosa: Conocimiento tradicional, valoración y manejo de las plantas forrajeras. Kurtziana 33: 153174.

SCARPA, G. F. 2012a. Las plantas en la vida de los criollos del oeste formoseño. Medicina, Ganadería, Alimentación y Viviendas Tradicionales. Rumbo Sur, Buenos Aires. 240 pp.

SCARPA, G. F. 2012b. Palos, yuyos, pencas, bejucos y pastos: Los nombres de las plantas y su clasificación etnobotánica por los criollos del Chaco Semiárido Norte (NE Salta - W Formosa). En ARENAS, P. (ed.), Etnobotánica en zonas áridas y semiáridas del Cono Sur de Sudamérica, pp. 117-144. Sigma, Buenos Aires.

SCARPA, G. F. \& C. N. ROSSO. 2014a. La etnobotánica moqoit inédita de Raúl Martínez Crovetto I: Descripción, actualización y análisis de la nomenclatura indígena. Bol. Soc. Arg. Bot. 49: 623-647.

SCARPA, G. F. \& C. N. ROSSO. 2014b. La etnobotánica moqoit inédita de Raúl Martínez Crovetto II: Descripción, actualización y análisis de usos de las plantas. Bonplandia 23: 133-141.

SCARPA, G. F. \& C. N. ROSSO (inédito). Etnobotánica histórica de grupos criollos de Argentina III: Puesta en valor y análisis de datos no medicinales para el Chaco Húmedo en la Encuesta Nacional de Folklore de 1921.

SCARPA, G. F., C. N. ROSSO \& L. M. ANCONATANI. 2016. Etnobotánica médica de grupos criollos de Argentina: Reconocimiento, análisis y puesta en valor de los datos presentados por el gobierno argentino en la exposición universal de París de 1889. Darwiniana Nueva Serie 4: 291-315.

STRAMIGLIOLI, C. 2007. Tintes naturales. Las teleras santiagueñas. El Autor, Buenos Aires. 192 pp.

TOLEDO, V. M \& N. BARRERA-BASSOLS. 2008. La memoria biocultural: La importancia ecológica de las sabidurías tradicionales. Icaria Editorial, Barcelona.

TRILLO, C., P. DEMAIO, S. COLANTONIO \& L. GALETTO. 2007. Conocimiento actual de plantas tintóreas por los pobladores de Guasapampa, provincia de Córdoba. Kurtziana 33: 65-71.

TROPICOS.ORG. 2014. Missouri Botanical Garden. http://www.tropicos.org/[Consulta:enero-abril 2017].

VIGNATI, M. A. 1941. Contribución a la etnobotánica indígena. El "pan" de los patagones protohistóricos. Not. Mus. La Plata (Sec. Antrop.) 6: 321-336.

Original recibido el 23 de mayo de 2017; aceptado el 11 de septiembre de 2017. 